\title{
Growth of the protozoan parasite Entamoeba histolytica in 5-azacytidine has limited effects on parasite gene expression Ibne Karim M Ali ${ }^{1}$, Gretchen $M$ Ehrenkaufer ${ }^{1}$, Jason A Hackney ${ }^{1}$ and Upinder Singh*1,2,3
}

Address: ${ }^{1}$ Department of Microbiology and Immunology, Stanford University School of Medicine, Stanford, California, 94305-5107, USA, 2Department of Internal Medicine and Division of Infectious Diseases, Stanford University School of Medicine, Stanford, California, 94305-5107, USA and 'Department of Medicine, Division of Infectious Diseases, S-143 Grant Building, 300 Pasteur Drive, Stanford, CA, 94305-5107, USA

Email: Ibne Karim M Ali - ikmali@stanford.edu; Gretchen M Ehrenkaufer - gehrenk@stanford.edu; Jason A Hackney - jhackney@stanford.edu; Upinder Singh* - usingh@stanford.edu

* Corresponding author

Published: 05 January 2007

BMC Genomics 2007, 8:7 doi:10.1/86/147|-2/64-8-7
Received: 06 September 2006

Accepted: 05 January 2007

This article is available from: http://www.biomedcentral.com/I47I-2164/8/7

(c) 2007 Ali et al; licensee BioMed Central Ltd.

This is an Open Access article distributed under the terms of the Creative Commons Attribution License (http://creativecommons.org/licenses/by/2.0), which permits unrestricted use, distribution, and reproduction in any medium, provided the original work is properly cited.

\begin{abstract}
Background: In higher eukaryotes DNA methylation regulates important biological functions including silencing of gene expression and protection from adverse effects of retrotransposons. In the protozoan parasite Entamoeba histolytica, a DNA methyltransferase has been identified and treatment with 5 -azacytidine (5-AzaC), a potent inhibitor of DNA methyltransferase, has been reported to attenuate parasite virulence. However, the overall extent of DNA methylation and its subsequent effects on global gene expression in this parasite are currently unknown.

Results: In order to identify the genome-wide effects of DNA methylation in $E$. histolytica, we used a short oligonucleotide microarray representing 9,435 genes ( $95 \%$ of all annotated amebic genes) and compared the expression profile of $E$. histolytica HM-I:IMSS parasites with those treated with $23 \mu \mathrm{M} 5$-AzaC for up to one week. Overall, $2.1 \%$ of genes tested were transcriptionally modulated under these conditions. 68 genes were upregulated and 131 genes down regulated (2-fold change; $\mathrm{p}$-value $<0.05$ ). Sodium-bisulfite treatment and sequencing of genes indicated that there were at least two subsets of genes with genomic DNA methylation in $E$. histolytica: (i) genes that were endogenously silenced by genomic DNA methylation and for which 5-AzaC treatment induced transcriptional de-repression, and (ii) genes that have genomic DNA methylation, but which were not endogenously silenced by the methylation. We identified among the genes down regulated by 5-AzaC treatment a cysteine proteinase (2.m00545) and lysozyme (52.m00 I 48) both of which have known roles in amebic pathogenesis. Decreased expression of these genes in the 5-AzaC treated $E$. histolytica may account in part for the parasites reduced cytolytic abilities.
\end{abstract}

Conclusion: This work represents the first genome-wide analysis of DNA-methylation in Entamoeba histolytica and indicates that DNA methylation has relatively limited effects on gene expression in this parasite. 


\section{Background}

Methylation is an enzymatic modification of DNA that occurs post replication and epigenetically contributes to transcriptional regulation. Many important biological processes are modulated by DNA methylation including regulation of gene expression [1], development [2], and control of retrotransposon elements [3]. DNA methylation is also responsible for maintenance of chromatin structure [4] and inactivation of chromosome X in female mammals [5]. DNA methyltransferases (DNMTs) catalyze DNA methylation, which in humans and higher eukaryotes occurs predominantly at the C5-cytosine (m5C) in CpG dinucleotides [6]. DNA methylation can silence genes by directly blocking the interaction of transcription factors to their regulatory sequences $[7,8]$. DNA methylation can also attract methyl-binding protein, which recruits histone deacetylases and histone methyltransferases, resulting in an inactive chromatin structure $[9,10]$. Defects in establishing or maintaining DNA methylation patterns are associated with a number of human diseases and conditions such as cancers [11], schizophrenia [12], and aging [13].

Entamoeba histolytica is a protozoan parasite and the causative agent of amebic dysentery and amebic liver abscesses. These diseases result in significant morbidity and mortality worldwide, especially in developing countries, where an estimated 50 million cases of invasive amebiasis result in up to 100,000 deaths annually [14]. An active DNA methyltransferase (Ehmeth) of the DNA methyltransferase 2 (DNMT2) family has been characterized in E. histolytica [15] and ribosomal DNA [15] and a heat shock protein 100 (EHsp100) gene [16] have been shown to be methylated in this parasite. Additionally, an amebic protein which binds preferentially to methylated DNA has recently been identified (E. histolytica methylated LINE binding protein, EhMLBP) [17]. Importantly E. histolytica strain HM-1:IMSS grown with 5-azacytidine (5-AzaC), a potent inhibitor of DNA methyltransferase, had been shown to have significantly reduced virulence in vitro and in vivo [15]. Furthermore, the decrease in parasite virulence was reversible upon removal of the drug, indicating that drug exposure likely did not cause significant permanent mutations in the E. histolytica genome sequence [15]. On the other hand, over expression of Ehmeth in E. histolytica resulted in accumulation of multinucleated cells, up regulation of heat shock protein 70 (HSP70) expression, and resistance to oxidative stress [18]. All these findings suggest that DNA methylation has important biological functions in this parasite.

Information on the effects of DNA methylation in simple eukaryotes is relatively limited. 5-AzaC treatment of Trypanosoma cruzi epimastigotes in culture induces active cell proliferation as evident from an increase in the cell number and [3H-methyl] thymidine incorporation into DNA [19]. DNA methylation increases during development of Dictyostelium discoideum and DNA methyltransferase mutant cells exhibit morphological defects in late development, indicating that DNA methylation has a regulatory role in Dictyostelium development [2]. In ciliates, cytosine methylation occurs in transposon-like elements in the course of macronuclear differentiation in Stylonychia lemnae [20] and 5-AzaC treatment induces encystment in Colpoda inflata [21].

Several microarray-based studies have demonstrated that inhibition of promoter methylation by a drug that inhibits DNA methyltransferase results in altered gene expression [22-25]. In Arabidopsis thaliana transcriptional profiling revealed that inhibition of DNA methylation by 5-Aza-2-deoxycytidine (5Aza-dC) altered the expression of $1.6 \%$ of genes tested, with 73 being up-regulated and 52 down-regulated by more than 3 fold [26]. Similarly 5 Aza-dC treatment of a human gastric cancer cell line caused up-regulation of about $1.5 \%$ of the genes by at least 16-fold [22]. Treatment of esophageal squamous carcinoma cells with $5 \mu \mathrm{M}$ of 5 -Aza-dC caused at least 3-fold or more up regulation of $1.92 \%$ of 12,599 genes [24].

In order to identify the genome-wide effects of DNA methylation on gene expression in E. histolytica, we performed transcriptional profiling of parasites treated with and without 5-AzaC. Using a short oligonucleotide microarray representing 9,435 of the predicted 9,938 open reading frames from E. histolytica [27] we identified 199 genes $(2.1 \%)$ as being modulated at least 2 -fold by 5 -AzaC. Of these, 68 genes were up-regulated and 131 genes down regulated. These data indicate that epigenetic gene silencing is operational in E. histolytica although it does not effect a large portion of the amebic genome.

\section{Results \\ Treatment with 5-AzaC did not significantly affect parasite growth but reduced virulence in vitro}

In order to elucidate the effects of inhibiting genomic DNA methylation in E. histolytica, we grew parasites in 23 $\mu \mathrm{M} 5$-AzaC for up to seven days with routine passaging and assessed growth rates and in vitro virulence. We used two different E. histolytica strains HM-1:IMSS and 200:NIH, both of which are considered virulent $[28,29]$. For E. histolytica HM-1:IMSS parasites exposed to $23 \mu \mathrm{M} 5$ AzaC there was some reduced growth at day 2, compared to the untreated control, however, the parasite numbers in subsequent days were consistently equivalent (Figure 1A). In E. histolytica 200:NIH treated with $23 \mu \mathrm{M}$ 5-AzaC, we did not observe any statistically significant effect on growth for up to seven days compared to the untreated control (Figure 1B). Additionally, we grew E. histolytica HM-1:IMSS for five consecutive days without routine sub- 
culturing, and did not observe any growth differences in parasites grown with or without $23 \mu \mathrm{M} 5$-AzaC (see Additional file $1 \mathrm{~A}$ ). We could not reliably grow parasites for $>5$ days without subculturing due to overcrowding of the cultures and parasite death. For the 200:NIH strain, the parasite numbers in 5-AzaC treated and untreated cultures were also equivalent at all time points tested, up to day 5 (data not shown). Under these conditions, we assessed the protein content per cell of E. histolytica HM-1:IMSS parasites at days 2, 3, 4, and 5 of growth, and found that there were no significant differences in protein content per cell between drug treated and untreated parasites or between parasites at different time points (see Additional file 1B). Similar data were observed for the 200:NIH strain (data not shown). We also grew the E. histolytica HM1:IMSS strain $( \pm 23 \mu \mathrm{M} 5$-AzaC) with routine subculturing every two days with an equal volume of culture medium and parasites passed at each time. Under these conditions, the growth of the parasites in $23 \mu \mathrm{M} 5$-AzaC was slightly reduced at day 2 , however the rate of growth was subsequently equivalent to the untreated control at days 4 and 6 (see Additional file 1C). Overall, these data indicate that there is not a substantial and sustained effect on the growth of the E. histolytica parasites for up to 6-7 days in the presence of $23 \mu \mathrm{M} 5$-AzaC.

For both E. histolytica HM-1:IMSS and E. histolytica 200:NIH, 5-AzaC exposure for 3 or 7 days resulted in parasites that were reduced in virulence $52 \%$ or $63 \%$ of untreated levels respectively at day 3 and $28 \%$ and $35 \%$ of untreated levels respectively at day 7) (Figure 1C). Exposure to 5 -AzaC at $23 \mu \mathrm{M}$ did not affect $\mathrm{CHO}$ cell viability and addition of $23 \mu \mathrm{M} 5$-AzaC to the parasites at the time of the CHO cell killing assay did not affect parasite virulence (data not shown). Thus the reduction in ability of the parasites to kill $\mathrm{CHO}$ cells was dependent on prior exposure of the parasites to 5-AzaC. Although this was an in vitro cell killing assay and thus an indirect measure of parasite virulence, our results correlate with previously published data of in vitro and in vivo virulence attenuation in E. histolytica HM-1:IMSS grown with $23 \mu \mathrm{M}$ of 5-AzaC for 1 week $[15,16]$. Since E. histolytica parasite strains are genomically diverse (as shown by comparative genomic hybridizations) [30] and have genome-wide expression differences [31], it was not clear if the effects of 5-AzaC could be generalized to other E. histolytica strains. We have now shown that two genetically distinct, but virulent, strains of E. histolytica, are similarly attenuated in their virulence potential by 5-AzaC treatment. Whether this virulence attenuation is due to a direct effect of the 5-AzaC on E. histolytica genomic DNA methylation, is due to some other effect on the parasite, or is simply an associative phenomenon, cannot be definitively stated at present.

\section{Microarray expression profiling reveals genes modulated by 5 -AzaC treatment}

In order to identify genes whose expression was modulated by 5 -AzaC treatment, expression profiling of 9,435 amebic genes was performed for untreated and 5-AzaC treated E. histolytica HM-1:IMSS. We chose to perform expression profiling with the E. histolytica HM-1:IMSS strain for a number of reasons: (i) this is the strain for which the genome sequence is available and the array was designed, (ii) transcriptome data are available for this strain from an invasive mouse model of colitis and can be used for comparative purposes [27], (iii) this is the strain for which there are published data for potential roles of the retrotransposon elements (long interspersed nuclear elements (LINEs) and short interspersed nuclear elements (SINEs)) in amebic pathogenesis and gene silencing [31,32], (iv) there are substantial genomic differences in coding and non-coding regions of the 200:NIH strain compared to HM-1:IMSS [30], and (v) the vast majority of relevant literature is for the HM-1:IMSS strain.

To identify genes affected by genomic DNA methylation, we chose to look at both early (3 days) and late (7 days) time points after 5-AzaC exposure. We chose the early time point to identify genes that are likely modulated by 5-AzaC as a primary effect (rather than a secondary downstream effect of expression changes in other genes). However, in case certain genomic regions were more resistant to the effects of 5-AzaC, we also analyzed the parasite transcriptome after seven days of drug exposure. Importantly, for both these time points, there were no significant effects on parasite growth rates and both time points gave consistently attenuated virulence phenotypes in both $E$. histolytica strains (Figure 1 and see Additional file 1).

Genes that are endogenously silenced by genomic DNA methylation should be transcriptionally upregulated under 5-AzaC treatment. We considered genes transcriptionally regulated if they were modulated at both time points of 5-AzaC treatment compared to the untreated controls (overall 2-fold change and p-value < 0.05). To confirm the array data, a subset of genes whose expression was modulated by 5 -AzaC exposure were tested by semiquantitative RT-PCR and in all cases the array data were confirmed (Figure 2; Table 1). A total of 199 transcripts (2.1\% of all amebic genes tested) were significantly modulated with 68 genes upregulated and 131 genes down regulated in 5-AzaC treated parasites compared to control, untreated parasites (Tables 2, 3, and see Additional File 4 ). Approximately $58 \%$ of these genes were annotated as hypothetical or of unknown function. Whether all the genes that were upregulated by 5-AzaC treatment are methylated or were secondarily controlled by other genes cannot be definitively stated. However, we required that genes be transcriptionally modulated at both early and 
(A)
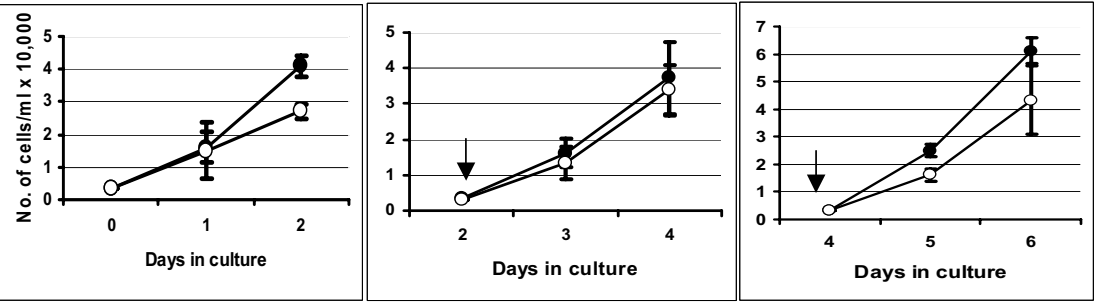

(B)

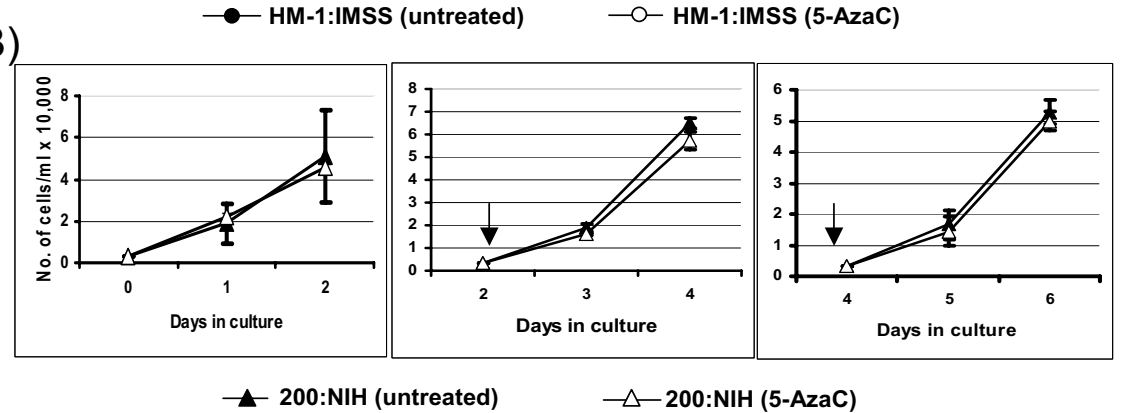

(C)

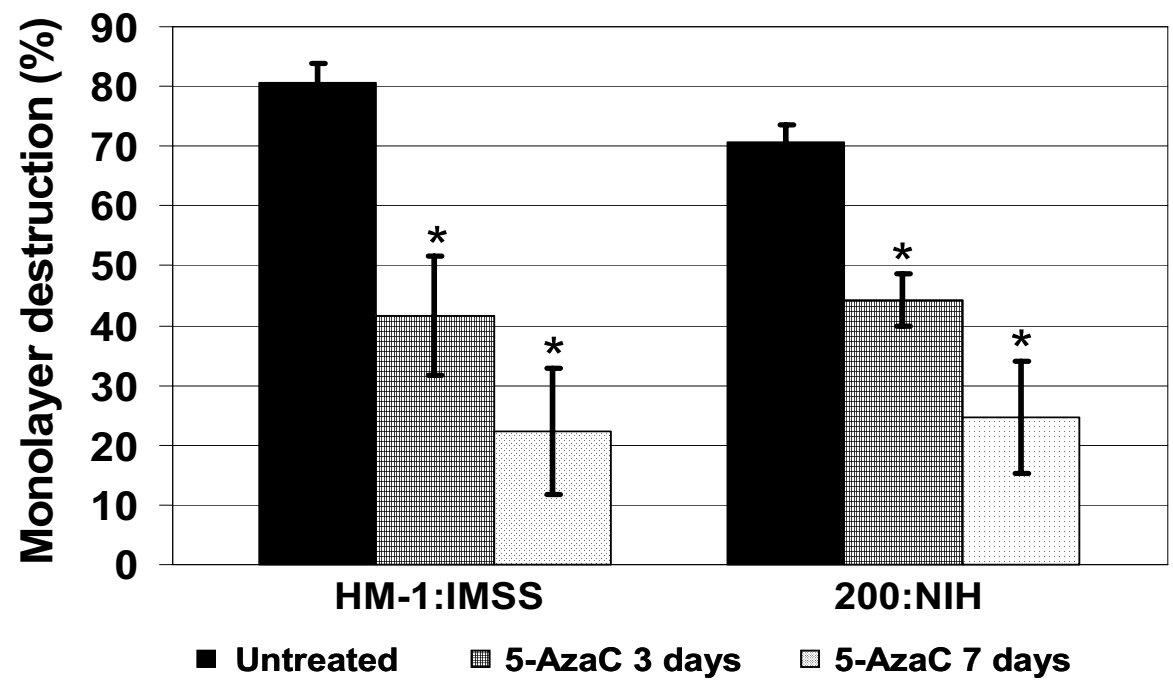

\section{Figure I}

Effects of 5-AzaC on E. histolytica growth and in vitro virulence. (A) and (B) Growth curves for untreated and 5-AzaC treated E. histolytica HM-I:IMSS and E. histolytica 200:NIH strains respectively. On day zero 50,000 trophozoites were inoculated in $15 \mathrm{ml}$ culture tubes and grown with or without $23 \mu \mathrm{M}$ 5-AzaC. On days two and four (marked by a downward arrow), 50,000 trophozoites were subcultured into fresh media and 5-AzaC added to the appropriate tubes. (C) Monolayer destruction of $\mathrm{CHO}$ cells by untreated, three-day, and seven-day 5-AzaC treated trophozoites of $E$. histolytica strains HM-I:IMSS and 200:NIH. In both parasite strains the 3-day and 7-day 5-AzaC treated parasites showed significantly decreased virulence compared to that with corresponding untreated parasites ( $p$-value $<0.05)$ (shown by $*$ ). 
late time points, thus hopefully minimizing the potential secondary downstream effects. Genes whose expression decreases with 5-AzaC treatment are expected to be secondary or downstream effects of regulation of another gene. Inhibition of genomic DNA methylation would not, to the best of our knowledge, be directly expected to repress gene expression [33].

Genomic regions previously known to be methylated in E. histolytica are the heat shock protein 100 (EHsp100), ribosomal RNA (rRNA), and heat shock protein 70 (HSP70), and the repetitive region EhMRS2 [16,18,34]. Of these, the only gene known to be transcriptionally modulated by DNA methylation is EHsp100 [16]. In the study by Bernes et al., the EHsp100 gene transcript could not be detected in untreated E. histolytica HM-1:IMSS parasites but was upregulated in 5-AzaC-treated and heatshocked parasites [16]. This gene is represented by locus 192.m00086 in the E. histolytica TIGR Genome Database [35] and represented by the 64.m00187_s_at probe set in our microarray. However, in our studies this probe set showed significant hybridization under standard culture conditions in E. histolytica HM-1:IMSS parasites and was not modulated by inhibition of DNA methylation (Table 4; see Additional file 4). This probe set was also showed significant hybridization in the 200:NIH strain (data not shown). Since this probe set also represented a number of other genes (111.m00116, 181.m00064, 365.m00018, 482.m00014, 493.m00033, 511.m00026, 82.m00144, and 872.m00009), we confirmed the array results by RTPCR using gene specific primers as designed by Bernes et al [16]. The RT-PCR analysis, specific to the EHsp100 gene, confirmed our microarray data and indicated that in our E. histolytica HM-1:IMSS strain the EHsp100 gene was expressed under baseline culture conditions and was not modulated by 5-AzaC treatment (see Additional file 2 ). Other genes associated with the heat shock or stress response were not expressed in our parasites under standard culture conditions, indicating that the parasite cultures were not generally stressed (see Additional file 4). The difference in basal EHsp100 gene expression between our cultures and those of Bernes, et al. [16] may be due to differences in the parasite strains. It has been shown that different clones of E. histolytica HM-1:IMSS have different expression levels for certain genes, including retrotransposons [31], and have other biologically distinct properties relating to gene silencing [36].

Using bisulfite treatment followed by sequencing of the coding and promoter regions we confirmed that the EHsp100 gene in our parasite strain was methylated (Table 4). However, the extent of DNA methylation in the promoter and coding regions of the EHsp100 gene in our HM-1:IMSS parasite clone was slightly lower compared to that of Bernes, et al. [16]. For example, position 45 of the promoter (according to the nucleotide positions referred to by Bernes, et al., [16]) was found to be unmethylated in 6 out of 6 clones tested in our HM-1:IMSS parasite strain while 2 out of 5 clones in Bernes' HM-1:IMSS showed evidence of methylation. Similarly, for other positions fewer clones in our strain showed methylation compared to their parasites (data not shown). Whether this slight difference in DNA methylation in our strain compared to that of Bernes, et al. [16] was responsible for the baseline higher expression under standard conditions is not clear at present. While our microarray does not contain probe sets for rRNA genes, other genes previously known to contain cytosine methylation such as HSP70 (218.m00068) were not modulated by 5-AzaC treatment. In fact, it has been shown that the expression of HSP70 is not regulated by its cytosine methylation [18]; thus, our data are consistent with this observation. We also identified other genes, whose transcription was marginally modulated (but which did not meet our 2-fold and p-value $<0.05$ cutoff) but whose promoters were methylated (687.m00016， 3.m00674， 160.m00098， 26.m00304) (Table 4).

Thus, there appear to be at least two subsets of genes in $E$. histolytica. First are those that are endogenously silenced by genomic DNA methylation and for which 5-AzaC treatment induces significant transcriptional de-repression (such as 141.m00082, 115.m00143, and 97.m00140). The second category of genes are those that have genomic DNA methylation, but are not endogenously silenced (such as EHsp100, HSP70, 687.m00016, 3.m00674, 160.m00098, 26.m00304) [18]. Whether the second category of genes (except for EHsp100 which is sensitive to 5-AzaC treatment) are more resistant to 5-AzaC [37] or are those in which the methylation profile is not due to methyltransferases but instead due to other factors, such as dsRNA-directed methylation [38], is not clear at present.

\section{RT-PCR confirmed the array data}

In order to confirm the microarray data, we isolated RNA from 5-AzaC treated and untreated E. histolytica HM1:IMSS, and performed semi-quantitative RT-PCR on five genes: two each from significantly up (115.m00143 and 141.m00082) and down-regulated gene sets (2.m00545 and 226.m00092), respectively, and one invariant gene (147.m00095), based on Affymetrix analysis. RT-PCR agreed with the microarray data for all five transcripts tested (Figure 2).

\section{Genomic DNA methylation apparently silences a small subset of amebic genes}

Of the total 199 genes modulated in 5-AzaC treated E. histolytica HM-1:IMSS, 68 (0.7\% of all amebic genes) were significantly up regulated by inhibition of genomic DNA methylation (Table 2 ). Approximately $72 \%$ of these were 
Table I: PCR primers used in study.

\begin{tabular}{|c|c|c|c|c|c|}
\hline \multicolumn{6}{|c|}{ (A) Primers used in RT-PCR } \\
\hline Probe set & Primer name & Direction & AT & Primer sequence $\left(5^{\prime}-3^{\prime}\right)$ & Target region \\
\hline \multirow[t]{2}{*}{ II5.m00I43_at } & $115 . \mathrm{m00|} 43 \mathrm{~F}$ & $\mathrm{~S}$ & $55^{\circ} \mathrm{C}$ & CCAAACGATACACACCCAGA & Coding \\
\hline & II5.m00I43R & AS & $55^{\circ} \mathrm{C}$ & GCAATTTGAAACTTCACATCACA & Coding \\
\hline \multirow[t]{2}{*}{ 141.m00082_at } & |4|.m00082F & $S$ & $55^{\circ} \mathrm{C}$ & TCATTTGGAATTGTTTATGTTGG & Coding \\
\hline & |4|.m00082R & AS & $55^{\circ} \mathrm{C}$ & TGCACTTCCAAAATCCGTTA & Coding \\
\hline \multirow[t]{2}{*}{ 2.m00545_at } & 2.m00545F & $S$ & $55^{\circ} \mathrm{C}$ & GCTGCCATGACTAATGCTGA & Coding \\
\hline & 2.m00545R & AS & $55^{\circ} \mathrm{C}$ & AGCAACAGCAACTGGTCCTT & Coding \\
\hline \multirow[t]{2}{*}{ 226.m00092_at } & $226 . \mathrm{m} 00092 \mathrm{~F}$ & $\mathrm{~S}$ & $55^{\circ} \mathrm{C}$ & GCAAACATGGGATACAGCAG & Coding \\
\hline & 226.m00092R & AS & $55^{\circ} \mathrm{C}$ & ACAAGGCGCTTGTTCAACTT & Coding \\
\hline
\end{tabular}

(B) Primers used in PCR from bisulfite treated DNA

\begin{tabular}{|c|c|c|c|c|c|}
\hline Probe set & Primer name & Direction & AT & Primer sequence (5' - 3') & Target region \\
\hline \multirow[t]{4}{*}{ 64.m00187_s_at } & EHsp5'bis* & $\mathrm{S}$ & $50^{\circ} \mathrm{C}$ & ATGAATAAGAAAGTGTGAATAATAG & Promoter \\
\hline & EHsp3'bis* & AS & $50^{\circ} \mathrm{C}$ & AACATTAATTCCACTATTTCCTACTA & Promoter \\
\hline & EHspl005* & $S$ & $50^{\circ} \mathrm{C}$ & TGAGTATTTAAAGGAACTTGAAG & Coding \\
\hline & EHsp3'bis* & AS & $50^{\circ} \mathrm{C}$ & AACATTAATTCCACTATTTCCTACTA & Coding \\
\hline \multirow[t]{2}{*}{ II5.m00I43_at } & II5.mPF & $S$ & $52^{\circ} \mathrm{C}$ & CTTGAAGGATAAAAAATAAGTCATATTTCTA & Promoter \\
\hline & II5.mPR & AS & $52^{\circ} \mathrm{C}$ & ATAATCTGCATGGCATATATTTCCTAATT & Promoter \\
\hline \multirow[t]{2}{*}{ II5.m00I43_at } & II $5 . \mathrm{mBCF}$ & $S$ & $48^{\circ} \mathrm{C}$ & ATGTTTGTATCTTATTTTCTATTTTTAAATTT & Coding \\
\hline & II5.mCR & AS & $48^{\circ} \mathrm{C}$ & GTTCCAGTACATACAATTTTACCT & Coding \\
\hline \multirow[t]{4}{*}{ 141.m00082_at } & |4|.mBPF & $S$ & $52^{\circ} \mathrm{C}$ & TATTGAACACTGCTCTAAATCCACT & Promoter \\
\hline & |4I.mBPR & AS & $52^{\circ} \mathrm{C}$ & GTGTAGTACTGAATAAACACTTTTCTT & Promoter \\
\hline & $14 \mid . \mathrm{mBCF}$ & $\mathrm{S}$ & $53^{\circ} \mathrm{C}$ & TTGATATAACTAATTCACCTACATTCCAA & Coding \\
\hline & $|4| . \mathrm{mBCR}$ & AS & $53^{\circ} \mathrm{C}$ & GATCCTTCTCCTATTTTCTTTTCTTCT & Coding \\
\hline \multirow[t]{2}{*}{ 97.m00140_at } & 97.mPF & $\mathrm{S}$ & $50^{\circ} \mathrm{C}$ & АТТАСТССТТСССТСТСТТСТT & Promoter \\
\hline & 97.mPR & AS & $50^{\circ} \mathrm{C}$ & CCATTRTCATTTCTCTCAACC & Promoter \\
\hline \multirow[t]{2}{*}{ 194.m00103_at } & 194.mPF & $\mathrm{S}$ & $50^{\circ} \mathrm{C}$ & GACTRCACCCAATTTTCCACCT & Promoter \\
\hline & 194.mPR & AS & $50^{\circ} \mathrm{C}$ & ССАТСССААТАААТТССТТСТT & Promoter \\
\hline \multirow[t]{2}{*}{ 687.m00016_at } & 687.mBPF & $S$ & $53^{\circ} \mathrm{C}$ & CTTTCARACACTTAAACAAATCTTCTTCA & Promoter \\
\hline & 687.mBPR & AS & $53^{\circ} \mathrm{C}$ & ARATTCTCTCAAATACACTTCCCAC & Promoter \\
\hline \multirow[t]{2}{*}{ 3.m00674_at } & 3.mBPF & $S$ & $49^{\circ} \mathrm{C}$ & GTTATTCAATTATACTTTATACCAAACA & Promoter \\
\hline & 3.mBPR & AS & $49^{\circ} \mathrm{C}$ & TCATTTTARTTCTTTTTTCTTATACCACT & Promoter \\
\hline \multirow[t]{2}{*}{ 160.m00098_at } & 160.mBPF & $S$ & $50^{\circ} \mathrm{C}$ & СТАATAAAATTTТСТTАСАССТААСТСА & Promoter \\
\hline & $160 . \mathrm{mBPR}$ & AS & $50^{\circ} \mathrm{C}$ & СТTСТTТАТTТTTТССАТААТАТTСТTТСТ & Promoter \\
\hline \multirow[t]{2}{*}{ 26.m00304_at } & 26.mBPF & $\mathrm{S}$ & $48^{\circ} \mathrm{C}$ & TAAAACTARACCATTTATTCAACAATT & Promoter \\
\hline & 26.mBPR & AS & $48^{\circ} \mathrm{C}$ & RRTTCTTCTTCCATAATTTATTATTA & Promoter \\
\hline \multirow[t]{4}{*}{ 2.m00545_at } & 2.mBPF & $S$ & $50^{\circ} \mathrm{C}$ & TTACTTCTCGTTATTCTATTAATATAAAC & Promoter \\
\hline & 2.mBPR & AS & $50^{\circ} \mathrm{C}$ & GATTATTTTTTGCCATCCATTTATCAA & Promoter \\
\hline & 2.mBCF & $S$ & $50^{\circ} \mathrm{C}$ & СТАAATTTACAAAAAAACTAATATACTСТC & Coding \\
\hline & 2.mBCR & AS & $50^{\circ} \mathrm{C}$ & TAGAGCCACCATTACATCCATTA & Coding \\
\hline \multirow[t]{4}{*}{ 226.m00092_at } & 226.mBPF & $S$ & $49^{\circ} \mathrm{C}$ & CTATTGATATTGAAATGCAAAAAACAAT & Promoter \\
\hline & 226.mBPR & AS & $49^{\circ} \mathrm{C}$ & TGATATATCAACTTAAACAAACTTACTA & Promoter \\
\hline & 226.mBCF & $S$ & $50^{\circ} \mathrm{C}$ & GTTCTTCTAGATTATTAAAAACCATTC & Coding \\
\hline & 226.mBCR & AS & $50^{\circ} \mathrm{C}$ & AACACTTCCTTTATCTATTTTATTTCC & Coding \\
\hline
\end{tabular}

Primers used, annealing temperatures, sequences, and their targets (gene promoters or coding regions) are listed for the (A) RT-PCR and (B) bisulfite sequencing studies. The probe set targeted, the primer name, direction of the primer, annealing temperature, primer sequence, and region of each gene targeted (coding or promoter) are shown. S refers to the sense primer; AS to the antisense primer; R represents either A or G. * indicates primers taken from Bernes, et al., 2005 [16]. 
Table 2: Genes up-regulated in 5-AzaC treated E. histolytica HM-I:IMSS parasites as compared to untreated controls.

\begin{tabular}{|c|c|c|c|c|}
\hline Probe set & Baseline expression level & Fold-change & p-value & Annotation \\
\hline 763.m00027_s_at ${ }^{a}$ & 0.01 & 28.97 & 0.024 & hypothetical protein \\
\hline 120.m00098_x_at & 0.01 & 14.35 & 0.011 & hypothetical protein \\
\hline 329.m00054_at & 0.01 & 13.06 & 0.017 & hypothetical protein \\
\hline 253.m0008I_x_at & 0.02 & 10.61 & 0.041 & hypothetical protein \\
\hline 16.m0030I_at & 0.01 & 9.75 & 0.006 & hypothetical protein \\
\hline 228.m00060_x_at & 0.02 & 9.43 & 0.007 & AIGI family protein, putative (GO:0004765) \\
\hline 244.m00069_x_at & 0.01 & 9.23 & 0.021 & hypothetical protein \\
\hline 37I.m0003I_x_at & 0.01 & 8.69 & 0.006 & BspA-like leucine rich repeat protein, putative \\
\hline 295.m00030_at & 0.02 & 8.11 & 0.036 & conserved hypothetical protein \\
\hline 64.m00I73_x_at & 0.01 & 7.95 & 0.043 & BspA-like leucine rich repeat protein, putative \\
\hline 94.m00।38_at & 0.02 & 7.09 & 0.033 & hypothetical protein \\
\hline 36.m00220_s_at ${ }^{\mathrm{b}}$ & 0.02 & 5.78 & 0.005 & hypothetical protein \\
\hline 432.m00029_x_at & 0.08 & 5.32 & 0.001 & conserved hypothetical protein \\
\hline 1087.m00005_at & 0.03 & 5.12 & 0.038 & hypothetical protein \\
\hline 40I.m00029_at & 1.11 & 4.97 & 0.022 & protein kinase, putative (GO:0005524) \\
\hline 92.m00177_x_at & 0.05 & 4.39 & 0.009 & hypothetical protein \\
\hline 86.m00156_s_atc & 0.09 & 4.06 & 0.036 & glutamine cyclotransferase, putative \\
\hline 287.m00045_x_at & 0.03 & 3.93 & 0.026 & hypothetical protein \\
\hline 450.m00030_at & 0.12 & 3.90 & 0.043 & hypothetical protein \\
\hline 2.m00587_x_at & 0.04 & 3.83 & 0.009 & hypothetical protein \\
\hline II5.m00I43_at* & 0.12 & 3.64 & 0.001 & transcription initiation factor TFIID, putative (GO:0003677) \\
\hline 420.m0002I_x_at & 0.03 & 3.59 & 0.007 & hypothetical protein \\
\hline 27.m00245_at & 0.03 & 3.55 & 0.017 & hypothetical protein \\
\hline 103.m00185_at & 6.55 & 3.32 & 0.023 & Fe-hydrogenase, putative (GO:0005489) \\
\hline 194.m00103_at* & 0.07 & 3.27 & 0.029 & protein kinase, putative (GO:0005524) \\
\hline 26.m00274_x_at & 0.07 & 3.22 & 0.039 & hypothetical protein \\
\hline 935.m00010_at & 0.11 & 3.15 & 0.009 & hypothetical protein \\
\hline 93.m00158_s_at ${ }^{d}$ & 0.10 & 3.10 & 0.014 & DNA mismatch repair protein mutS, putative (GO:0006298) \\
\hline 97.m00140_at* & 0.08 & 3.10 & 0.006 & hypothetical protein \\
\hline 138.m00086_x_at & 4.75 & 3.09 & 0.023 & hypothetical protein \\
\hline 66.m00163_s_at & 0.03 & 3.08 & 0.010 & hypothetical protein \\
\hline 12.m00286_at & 0.04 & 3.06 & 0.025 & hypothetical protein \\
\hline 295.m00044_x_at & 0.07 & 3.04 & 0.017 & conserved hypothetical protein \\
\hline 141.m00082_at* & 0.32 & 2.98 & 0.010 & protein kinase, putative (GO:0004672) \\
\hline 267.m00069_at & 0.04 & 2.96 & 0.001 & hypothetical protein \\
\hline 4.m00648_x_at & 0.04 & 2.89 & 0.032 & hypothetical protein \\
\hline II2.m00II9_at & 0.04 & 2.85 & 0.035 & hypothetical protein \\
\hline 472.m00058_s_ate & 0.08 & 2.83 & 0.008 & hypothetical protein \\
\hline 204.m00098_x_at & 0.22 & 2.77 & 0.008 & hypothetical protein \\
\hline 583.m000 II_at & 0.41 & 2.69 & 0.026 & hypothetical protein \\
\hline 62.m00/74_x_at & 0.06 & 2.66 & 0.037 & hypothetical protein \\
\hline 55.m00I64_at & 0.07 & 2.63 & 0.002 & hypothetical protein \\
\hline 273.m00075_x_at & 0.05 & 2.59 & 0.042 & hypothetical protein \\
\hline
\end{tabular}


Table 2: Genes up-regulated in 5-AzaC treated E. histolytica HM-I:IMSS parasites as compared to untreated controls. (Continued)

\begin{tabular}{|c|c|c|c|c|}
\hline 249.m00077_x_at & 0.06 & 2.55 & 0.049 & hypothetical protein \\
\hline 289.m00092_at & 0.05 & 2.53 & 0.014 & hypothetical protein \\
\hline 464.m00030_at & 0.05 & 2.53 & 0.010 & hypothetical protein \\
\hline I.m00665_at & 1.11 & 2.53 & 0.046 & hypothetical protein \\
\hline 5I.m00/50_x_at & 0.05 & 2.49 & 0.009 & hypothetical protein \\
\hline 159.m00103_x_at & 0.43 & 2.44 & 0.044 & protein kinase, putative (GO:0004672) \\
\hline 19.m00288_at & 0.07 & 2.36 & 0.005 & hypothetical protein \\
\hline 308.m00054_x_at & 0.05 & 2.34 & 0.009 & hypothetical protein \\
\hline 5.m00447_x_at & 0.12 & 2.33 & 0.016 & hypothetical protein \\
\hline 5I.m00167_at & 0.05 & 2.33 & 0.042 & hypothetical protein \\
\hline 27.m00266_x_at & 0.06 & 2.30 & 0.050 & ELL complex EAP30 subunit, putative \\
\hline 222.m00072_at & 0.09 & 2.30 & 0.040 & SPRY domain protein \\
\hline I83.m0009I_x_at & 8.10 & 2.30 & 0.026 & acyl-CoA synthetase, putative (GO:0008I52) \\
\hline 289.m00067_s_at ${ }^{f}$ & 0.09 & 2.30 & 0.004 & short chain dehydrogenase family protein \\
\hline 43.m00197_x_at & 7.97 & 2.24 & 0.024 & cell adhesion protein (GO:0007/55) \\
\hline 54.m00234_s_atg & 1.09 & 2.22 & 0.037 & hypothetical protein (GO:0005554) \\
\hline 4.m006/3_x_at & 0.12 & 2.21 & 0.007 & hypothetical protein \\
\hline 48.m00224_s_at ${ }^{\mathrm{h}}$ & 0.71 & 2.21 & 0.018 & acetyltransferase, putative \\
\hline 75.m00I56_x_at & 0.11 & 2.17 & 0.007 & myotubularin, putative \\
\hline 25.m00258_x_at & 0.38 & 2.16 & 0.032 & hypothetical protein \\
\hline 34.m00243_x_at & 4.14 & 2.15 & 0.028 & $\begin{array}{l}\text { glucosamine 6-phosphate } \mathrm{N} \text {-acetyltransferase, putative } \\
\text { (GO:0008080) }\end{array}$ \\
\hline 314.m00052_x_at & 0.07 & 2.12 & 0.041 & hypothetical protein \\
\hline 21.m00282_at & 0.21 & 2.08 & 0.038 & hypothetical protein \\
\hline 528.m00022_at & 0.10 & 2.03 & 0.018 & hypothetical protein \\
\hline 48.m00192_at & 0.17 & 2.01 & 0.013 & hypothetical protein \\
\hline
\end{tabular}

a763.m00027_s_at also represents 190.m00085 (hypothetical protein), 239.m00065 (hypothetical protein), $278 . m 00067$ (hypothetical protein), 330.m00074 (hypothetical protein), 43.m00 I I (hypothetical protein) and 458.m0006I (hypothetical protein)

b36.m00220_s_at also represents 36.m00212 (hypothetical protein)

86.m00 I56_s_at also represents II 9.m00 I35 (glutamine cyclotransferase, putative)

d93.m00158_s_at also represents 153.m0009I (DNA mismatch repair protein mutS, putative)

e472.m00058_s_at also represents 361.m00052 (hypothetical protein)

f289.m00067_s_at also represents 180.m00106 (short chain dehydrogenase family protein)

854.m00234_s_at also represents 169.m00 32 (hypothetical protein) and 406.m00049 (hypothetical protein)

h48.m00224_s_at also represents 309.m00047 (acetyltransferase, putative)

The probe set, baseline expression value in untreated $E$. histolytica HM-I:IMSS trophozoites, fold change in 5-AzaC treated parasites, p-value, and gene annotation are shown. Genes in bold are those for which RT-PCR confirmation was performed. Genes in italics are genes whose expression is significantly higher in $E$. histolytica Rahman compared to $E$. histolytica HM-I:IMSS ( $\mathrm{p}$-value 0.0002 ). Genes with normalized expression values $>0.20$ can routinely be detected by RT-PCR. Genes marked by * are those for which bisulfite sequencing was performed. For annotations, GO IDs are given where available and are provided within parentheses. 
Table 3: A subset of genes down-regulated in 5-AzaC treated E. histolytica HM-I:IMSS parasites as compared to untreated controls.

\begin{tabular}{lccll}
\hline Probe set & Baseline expression & Fold-change & p-value & Annotation \\
\hline Potentially virulence associated & 4.12 & & & \\
2.m00545_at*t & 0.96 & 0.27 & 0.033 & cysteine proteinase, putative (GO:0006508) \\
52.m00148_at & 6.21 & 0.46 & 0.018 & lysozyme, putative \\
I.m00663_at & & 0.36 & 0.006 & myosin calcium-binding light chain, putative (GO:0005509) \\
& & & \\
Protein kinases & 1.76 & & & \\
35.m00259_at & 3.42 & 0.48 & 0.013 & protein kinase, putative (GO:0005524) \\
67.m0009I_x_at & 0.39 & 0.37 & 0.033 & protein kinase, putative (GO:0005524) \\
99.m00190_s_at & 0.51 & 0.46 & 0.040 & protein kinase, putative (GO:0006468) \\
466.m00033_x_at & 2.29 & 0.47 & 0.003 & protein kinase, putative (GO:0005524) \\
264.m00068_at & & 0.44 & 0.029 & protein kinase, putative (GO:0005524) \\
& & & \\
GTPases & 2.39 & & & \\
I06.m00140_at & 0.20 & 0.48 & 0.025 & Rap Ran GTPase activating protein, putative \\
2.m00606_x_at & 0.34 & 0.36 & 0.005 & Rab family GTPase (GO:0005524) \\
226.m00092_at* & 4.28 & 0.44 & 0.008 & Rab family GTPase \\
30.m00257_at & 3.22 & 0.50 & 0.023 & Rab family GTPase (GO:0005524) \\
34.m00273_x_at & 2.21 & 0.43 & 0.040 & Rab family GTPase (GO:0005524) \\
71.m00153_x_at ${ }^{\epsilon}$ & 1.15 & 0.47 & 0.002 & Rho family GTPase (GO:0005525) \\
8.m00366_s_at & 4.88 & 0.46 & 0.021 & Rho GTPase activating protein, putative \\
17I.m00089_at & & 0.35 & 0.044 & GTPase activating protein, putative (GO:0003924) \\
& & &
\end{tabular}

Genes with decreased expression in E. histolytica (Rahman) compared to E. histolytica (HM-I:IMSS)

$\begin{array}{lccll}\text { 108.m00122_at } & 32.12 & 0.21 & 0.036 & \text { hypothetical protein } \\ \text { 136.m00107_at } & 1.20 & 0.38 & 0.030 & \text { hypothetical protein } \\ \text { 22.m00298_at } & 4.12 & 0.43 & 0.002 & \text { hypothetical protein } \\ \text { 297.m0006I_at } & 5.00 & 0.35 & 0.010 & \text { hypothetical protein } \\ \text { 32.m00239_at } & 0.93 & 0.46 & 0.039 & \text { N-acetylglucosaminyl transferase, putative } \\ \text { 37.m00215_at } & 1.90 & 0.46 & 0.035 & \text { hypothetical protein } \\ \text { 442.m00023_x_at } & 0.82 & 0.44 & 0.006 & \text { hypothetical protein } \\ \text { 460.m00024_s_atb } & 2.18 & 0.27 & 0.015 & \text { hypothetical protein }\end{array}$

Genes overlap with day-I \& day-29 significantly up-regulated genes from in vivo mouse model (Gilchrist et al, 2006) ${ }^{f}$

$\begin{array}{lllll}\text { 15.m00302_at } & 4.05 & 0.41 & 0.030 & \text { hypothetical protein } \\ \text { 2.m00545_at* } & 4.12 & 0.27 & 0.033 & \text { cysteine proteinase, putative (GO:0006508) } \\ \text { 67.m0009I_x_at } & 3.42 & 0.37 & 0.033 & \begin{array}{l}\text { protein kinase, putative (GO:0005524) } \\ \text { 71.m00153_x_at }\end{array} \\ & 2.21 & 0.47 & 0.002 & \text { Rho family GTPase (GO:0005525) } \\ \text { Miscellaneous } & & & & \\ \text { 338.m00049_s_atc } & 4.30 & & & \\ \text { 10.m00349_x_at } & 4.30 & 0.42 & 0.020 & \text { LIM domain protein (GO:0008270) } \\ \text { 35.m00253_at } & 1.74 & 0.44 & 0.024 & \text { paxillin, putative (GO:0008270) } \\ \text { 646.m0002I_s_at } & 0.36 & 0.26 & 0.036 & \text { iron-sulfur flavoprotein, putative (GO:00061 I8) } \\ \text { 90.m00179_at } & 1.31 & 0.40 & 0.009 & \text { iron-sulfur flavoprotein, putative } \\ \text { 139.m00II8_at } & 3.90 & 0.46 & 0.044 & \text { amino acid transporter, putative (GO:0006865) }\end{array}$

a8.m00366_s_at also represents 58.m00I70 (Rho GTPase activating protein, putative)

b460.m00024_s_at also represents 353.m00048 (hypothetical protein) and 353.m00049 (hypothetical protein)

c338.m00049_s_at also represents 321 I.m00056 (LIM domain protein)

The probe set, baseline expression value in untreated $E$. histolytica HM-I:IMSS trophozoites, fold change in 5-AzaC treated parasites, $\mathrm{p}$-value, and gene annotation are shown. Genes are clustered according to functional categories. Genes in bold are those for which RT-PCR confirmation was performed. Genes with normalized expression values $>0.20$ can routinely be detected by RT-PCR. Genes marked by $*$ are those for which bisulfite sequencing was performed. Genes that were significantly upregulated in E. histolytica HM-I:IMSS trophozoites passed through mice are obtained from Gilchrist et al [27] and are indicated by $t$. For annotations, GO IDs are given where available and are provided within parentheses. 


\section{E. histolytica HM-1:IMSS cDNA}

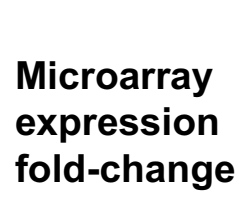

3.64

2.98

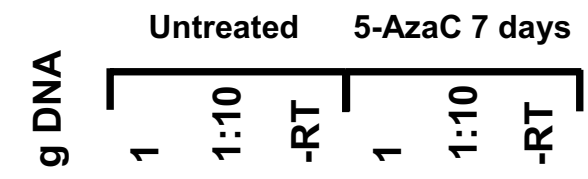

0.27
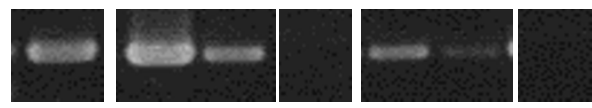

0.44
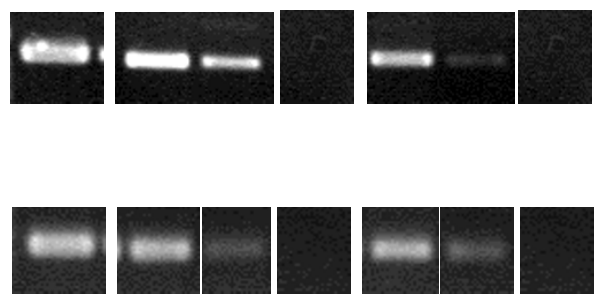

115.m00143

(transcription initiation factor TFIID, putative)

141.m00082

(protein kinase, putative)

\section{2. $\mathrm{m} 00545$}

(cysteine proteinase, putative)

226.m00092

(Rab family GTPase)

147.m00095

(RNA polymerase II L)

\section{Figure 2}

Verification of array data by RT-PCR. Array data were confirmed for a subset of genes by semi-quantitative RT-PCR. Total RNA was isolated from untreated and 5-AzaC treated parasites (7 days) and subjected to RT-PCR. Sequential I:I0 dilutions of cDNA were used as template for the PCR and a genomic DNA and minus RT control (-RT) were included. The microarray expression fold-change for each gene is shown based on average array data from 3 day and 7 day 5 -AzaC treated parasites. Two genes (I I5.m00I43 and I4I.m00082) that were predicted to be upregulated (based on array data) after 5-AzaC exposure were confirmed by RT-PCR. Two genes (2.m00545 and 226.m00092) that were predicted to be down-regulated (based on array data) after 5-AzaC exposure were confirmed by RT-PCR. A gene whose expression did not change (based on array data) with 5-AzaC exposure (147.m00095) was found to be unchanged in the two conditions by RT-PCR. Primers used are given in Table $\mathrm{I}$.

annotated as hypothetical proteins. Among the others were four putative protein kinases (401.m00029, 194.m00103, 141.m00082, and 159.m00103), two BspAlike leucine rich repeat protein genes (371.m00031 and 64.m00173), transcription initiation factor TFIID (115.m00143), and a DNA mismatch repair protein gene (93.m00158). There are two other putative transcription initiation factor TFIIDs annotated in the E. histolytica genome (324.m00040 and 40.m00208), both of which were expressed in detectable levels in untreated HM1 :IMSS parasites and were not regulated by 5 -AzaC treatment (see Additional file 4). It is not clear whether these two TFIID genes contain genomic DNA methylation. In contrast, the 115.m00143 gene had very low basal gene expression and was up regulated in 5-AzaC treated parasites, and has genomic DNA methylation of the coding region (Table 4 ). To the best of our knowledge, no such basal transcription factors have been shown to be modulated by DNA methylation in other systems. In prokaryotes DNA methylation is involved in DNA mismatch repair, and it was interesting to see that the amebic DNA mismatch repair gene was also regulated by DNA methylation [39].

Overall, 53 genes went from undetectable baseline expression (microarray signal $<0.2$ ) to a detectable expression levels after treatment by 5-AzaC; only 33 genes were up regulated by $\geq 3$-fold, and only 4 up-regulated by $\geq 10$ - 
$\$$ Table 4: Compilation of bisulfite treatment and sequencing results.

\begin{tabular}{|c|c|c|c|c|c|c|c|c|}
\hline \multirow[t]{2}{*}{ Probe set } & \multirow{2}{*}{$\begin{array}{c}\text { Baseline } \\
\text { expression value }\end{array}$} & \multirow[t]{2}{*}{ Fold change } & \multirow[t]{2}{*}{ p-value } & \multirow[t]{2}{*}{ Annotation } & \multicolumn{2}{|c|}{ Promoter region } & \multicolumn{2}{|c|}{ Coding region } \\
\hline & & & & & Total bp analyzed & $\begin{array}{l}\text { \# methylated cytosines/\# } \\
\text { total cytosines }\end{array}$ & Total bp analyzed & $\begin{array}{c}\text { \# methylated cytosines/\# } \\
\text { total cytosines }\end{array}$ \\
\hline \multicolumn{9}{|l|}{ Control genes } \\
\hline 64.m00187 & 14.05 & 0.90 & 0.731 & Hspl00 & 455 & $10 / 62$ & 397 & $48 / 48$ \\
\hline 64.m00I87** & 14.05 & 0.90 & 0.731 & Hspl00** & ND & ND & 397 & $0 / 48$ \\
\hline \multicolumn{9}{|c|}{ Significantly upregulated } \\
\hline |41.m00082 & 0.32 & 2.98 & 0.010 & protein kinase, putative & 308 & $36 / 36$ & 73 & $13 / 13$ \\
\hline $115 . \mathrm{m} 00143$ & 0.12 & 3.64 & 0.001 & $\begin{array}{l}\text { transcription initiation } \\
\text { factor TFIID, putative }\end{array}$ & 266 & $0 / 27$ & 254 & $5 / 40$ \\
\hline 97.m00140_at & 0.08 & 3.10 & 0.006 & hypothetical protein & 248 & $59 / 59$ & 110 & $23 / 23$ \\
\hline \multicolumn{9}{|c|}{ Marginally upregulated } \\
\hline 687.m00016_at & 12.16 & 18.68 & 0.091 & hypothetical protein & 328 & $18 / 18$ & ND & ND \\
\hline 3.m00674_at & 0.62 & 2.17 & 0.089 & hypothetical protein & 143 & $16 / 16$ & ND & ND \\
\hline 160.m00098_at & 11.46 & 1.72 & 0.112 & hypothetical protein & 244 & $16 / 16$ & ND & ND \\
\hline 26.m00304_at & 0.54 & 1.64 & 0.086 & hypothetical protein & 115 & $19 / 19$ & ND & ND \\
\hline \multicolumn{9}{|c|}{ Significantly downregulated } \\
\hline 226.m00092_at & 0.343 & 0.34 & 0.008 & Rab family GTPase & 347 & $0 / 27$ & 41 & $0 / 6$ \\
\hline
\end{tabular}

64.m00I87_s_at also represents III.m00II6, I8I.m00064, I92.m00086, 365.m000I8, 482.m000I4, 493.m00033, 5II.m00026, 82.m00I44, and 872.m00009.

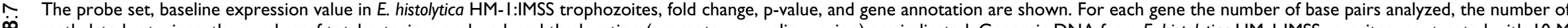

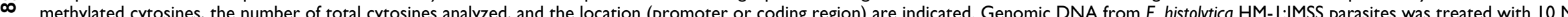

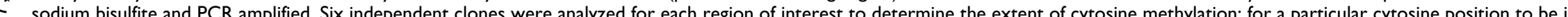

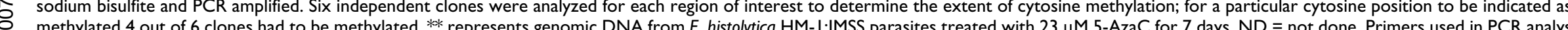

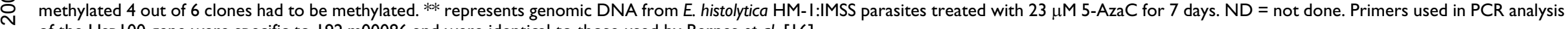
y of the Hspl00 gene were specific to 192.m00086 and were identical to those used by Bernes et al. [16] 
fold (Table 2). Thus, cytosine methylation apparently silences a relatively small number of amebic genes. As we have shown that $23 \mu \mathrm{M}$ 5-AzaC treatment for seven days was adequate for inhibiting methylation of the EHsp100 gene (Table 4), we disfavor a technical reason for this observation. However, we cannot exclude that this parasite contains other types of rare DNA methylation (adenine methylation or $\mathrm{N}-4$ cytosine methylation) [40-42], which remained unaffected by 5-AzaC treatment or that some amebic genomic regions have 5-methylcytosine that is resistant to $23 \mu \mathrm{M}$ of $5 \mathrm{AzaC}$ treatment. In Arabidopsis thaliana treatment with 5 -Aza-dC resulted in up-regulation of $0.9 \%$ of all genes in the array by $\geq 3$-fold [26]. This suggests that DNA methylation silences a relatively small number of genes in these two systems.

\section{Identification of genomic DNA methylation by bisulfite treatment and DNA sequencing}

It has been previously shown that the E. histolytica HM1:IMSS EHsp100 gene contained methylation in both the promoter and coding regions [16]. In order to confirm these data for our E. histolytica HM-1:IMSS strain, we performed a bisulfite reaction followed by strand-specific PCR of the EHsp100 gene. This procedure converts unmethylated cytosine residues to uracil, giving rise to thymine after amplification by PCR [43]. Only methylated cytosines are refractory to the deamination and are still seen as cytosines after PCR amplification. We demonstrated that the EHsp100 gene is methylated at both the coding and promoter regions and that $5-\mathrm{AzaC}$ treatment ( $23 \mu \mathrm{M}$ for 7 days) significantly inhibited methylation of this gene (Table 4). The level of demethylation we observed was similar to that observed by Bernes, et al. [16]. This confirmed that the $5-\mathrm{AzaC}$ was working as expected under our usage conditions.

In order to determine the extent of genomic DNA methylation in genes that were transcriptionally up regulated by 5-AzaC treatment, we performed sodium bisulfite treatment, PCR and sequencing of three genes significantly upregulated by 5-AzaC treatment (141.m00082, 97.m00140, and 115.m00143). These three genes had extremely low basal gene expression $(0.12 \pm 0.07)$ (median \pm standard error). We identified that two genes (141.m00082 and 97.m00140) contained cytosine methylation in both coding and corresponding promoter regions, while the third one (115.m00143) showed only limited methylation in the coding region (Table 4). Cytosine methylation in the coding region has been implicated in gene silencing in other systems [44] and appears to be responsible for the endogenous silencing of the 115.m00143 gene in E. histolytica. Overall the trend was for greater methylation in coding than promoter regions, as also seen by Bernes, et al. [16]. Thus, our microarray data identified novel genes whose expression was endogenously silenced by genomic DNA methylation.

Since the number of genes that were apparently regulated by DNA methylation was limited, we investigated whether genes that were somewhat transcriptionally modulated (but that did not meet our significance fold-change or p-value criteria) may also be genomically methylated. Four such genes were subjected to bisulfite treatment and sequencing: 687.m00016, 3.m00674, 160.m00098, and 26.m00304. We picked genes that were transcriptionally upregulated early (day 3 of 5-AzaC treatment) (see Additional file 4) in order to improve our chances of finding genes partially regulated by methylation. Surprisingly, all four genes had substantial methylation in their promoter regions (Table 4). Interestingly, despite the significant extent of genomic DNA methylation, these four genes were not transcriptionally silenced under basal conditions (basal expression levels, $6.04 \pm 3.25$ ) (median \pm standard error). A similar trend was previously noticed for the HSP70 gene, which has genomic methylation, but is not transcriptionally modulated by DNA methylation [18]. Additionally, in our strain of E. histolytica HM-1:IMSS, the EHsp100 gene is methylated but not endogenously silenced or transcriptionally modulated by 5-AzaC treatment (Table 4).

Thus, the extent of genomic DNA methylation in E. histolytica is likely greater than that indicated by the expression profiling as not all genomic regions that are methylated appear to be either transcriptionally silenced or substantially regulated by 5 -AzaC treatment. We do not feel that this represents a technical flaw (e.g. the amount of 5-AzaC used or duration of drug exposure) as $23 \mu \mathrm{M} 5$-AzaC for 7 days did completely abolish methylation at the Hsp100 coding region (Table 4). Additionally, higher does of 5$\mathrm{AzaC}(50 \mu \mathrm{M}$ and higher) are rapidly lethal to the parasite (our observations and [15]). As mentioned earlier, each gene that is methylated in E. histolytica does not necessarily respond to 5-AzaC treatment [18]. Similar observations have also been made in several insect systems. DNA methylation of defensin gene in the lepidopteran Mamestra brassicae is not involved in gene silencing as it is constitutively expressed [45]. Likewise, highly expressed genes in Myzus persicae [46,47] and Planococcus citri $[48,49]$ contain DNA methylation.

As expected, a gene whose expression levels significantly decreased after 5-AzaC treatment showed no cytosine methylation (226.m00092). Genes whose expression decreases after exposure to 5-AzaC would not be expected to be directly transcriptionally modulated by drug treatment, but likely change expression levels as a downstream effect of other transcriptional changes in the parasites. 
The majority of genomic DNA methylation in E. histolytica is not at CG di-nucleotides

In most systems, genomic DNA methylation occurs at CpG dinucleotides [50]. The skewed AT content of the amebic genome ( $75 \% \mathrm{~A} / \mathrm{T})$ predicts that methylation will frequently not occur at CpG dinucleotides [51]. The majority of methylations we identified were located in non-CpG sites, confirming previous data for the EHsp100 gene [16]. Non-CpG methylation was also detected in Entamoeba invadens [52]. In order to determine if we could bioinformatically predict the location of potential DNA methylation in E. histolytica genomic DNA, we analyzed the frequencies of mono- and di-nucleotides in genes transcriptionally regulated by 5 -AzaC compared to the whole genome. No significant differences in any of the mono or di-nucleotides were identified in up-regulated or down-regulated genes compared to the whole genome (Table 5). Thus, in the E. histolytica genome the frequency of the mono- or di-nucleotide occurrence was in itself not predictive of transcriptional regulation by genomic DNA methylation.

\section{Genes adjacent to retrotransposable elements are not} substantially silenced by genomic DNA methylation Retrotransposable elements can have substantial effects on genome structure and gene expression [53]. One method by which they can modulate gene expression is by regulating the expression of adjacent genes by methylation [54]. Retrotransposable elements are abundant in $E$. histolytica and some are maintained in hundreds of copies per genome [55]. Previously we have identified that two such retrotransposable elements, LINEs and SINEs, have higher expression in virulent strains of E. histolytica HM1:IMSS compared with nonvirulent Entamoeba [31]. In the reptile parasite Entamoeba invadens the reverse transcriptase of LINE (RT LINE) contains DNA methylation and it has been suggested that both E. invadens and E. histolytica possess a mechanism for DNA methylation of LINE retrotransposons [52]. It is also not clear how many fully functional LINE and SINE elements are present in $E$. histolytica (the majority of those that are sequenced are mutated/truncated) but we do know that at least some of the LINE and SINE elements are transcribed [31].

We were unable to detect the transcriptional profile of LINEs/SINEs as there are no probe sets representing these regions in our microarray. We wished to determine if genes adjacent to LINEs or SINEs were preferentially modulated by 5 -AzaC treatment. The normalized expression values for all genes adjacent to LINEs or SINEs were 0.761 \pm 0.09 (median \pm std error) and $0.509 \pm 0.362$ (median \pm std error), respectively, in untreated E. histolytica HM1 :IMSS, and $0.633 \pm 0.207$ (median \pm std error) and 0.449 \pm 0.786 (median \pm std error), respectively, in 5-AzaC

Table 5: Relative frequencies of mono- and dinucleotides in 5-AzaC modulated genes and in the whole genome.

\begin{tabular}{|c|c|c|c|c|c|c|c|}
\hline \multirow[b]{2}{*}{ Nucleotide } & & \multicolumn{2}{|c|}{ Whole genome } & \multicolumn{2}{|c|}{ Up-regulated genes } & \multicolumn{2}{|c|}{ Down-regulated genes } \\
\hline & & Coding & Promoter & Coding & Promoter & Coding & Promoter \\
\hline \multirow[t]{4}{*}{ Mononucleotide } & $A$ & 0.36 & 0.40 & 0.42 & 0.40 & 0.40 & 0.40 \\
\hline & $\mathrm{C}$ & 0.14 & 0.11 & 0.11 & 0.11 & 0.11 & 0.11 \\
\hline & G & 0.14 & 0.12 & 0.16 & 0.12 & 0.15 & 0.12 \\
\hline & $\mathrm{T}$ & 0.36 & 0.36 & 0.31 & 0.37 & 0.34 & 0.36 \\
\hline \multirow[t]{16}{*}{ Dinucleotide } & AA & 0.14 & 0.19 & 0.18 & 0.18 & 0.17 & 0.19 \\
\hline & $A C$ & 0.04 & 0.04 & 0.04 & 0.04 & 0.04 & 0.04 \\
\hline & AG & 0.05 & 0.05 & 0.06 & 0.05 & 0.06 & 0.05 \\
\hline & AT & 0.12 & 0.12 & 0.12 & 0.13 & 0.13 & 0.12 \\
\hline & CA & 0.06 & 0.05 & 0.06 & 0.05 & 0.06 & 0.05 \\
\hline & $\mathrm{CC}$ & 0.02 & 0.01 & 0.02 & 0.01 & 0.01 & 0.01 \\
\hline & CG & 0.01 & 0.01 & 0.01 & 0.01 & 0.01 & 0.01 \\
\hline & $\mathrm{CT}$ & 0.05 & 0.04 & 0.03 & 0.04 & 0.04 & 0.04 \\
\hline & GA & 0.06 & 0.06 & 0.08 & 0.05 & 0.07 & 0.05 \\
\hline & GC & 0.01 & 0.01 & 0.01 & 0.01 & 0.01 & 0.01 \\
\hline & GG & 0.02 & 0.02 & 0.02 & 0.01 & 0.02 & 0.01 \\
\hline & GT & 0.04 & 0.04 & 0.04 & 0.04 & 0.04 & 0.04 \\
\hline & TA & 0.09 & 0.11 & 0.09 & 0.11 & 0.10 & 0.11 \\
\hline & TC & 0.06 & 0.05 & 0.04 & 0.05 & 0.04 & 0.05 \\
\hline & TG & 0.06 & 0.05 & 0.06 & 0.05 & 0.06 & 0.05 \\
\hline & $\mathrm{TT}$ & 0.14 & 0.15 & 0.11 & 0.16 & 0.13 & 0.16 \\
\hline
\end{tabular}

The frequency of each mono and di-nucleotide was calculated for the entire genome and for the coding and promoter regions of the genes up and down-regulated by 5 -AzaC. No specific association of any given mono or di-nucleotide frequency with genes that are responsive to 5 -AzaC compared to the whole genome was identified. 
treated E. histolytica HM-1:IMSS. Thus, we did not identify any significant association of genes that were modulated by 5 -AzaC and their genomic proximity to LINE or SINE elements compared with untreated parasites. This finding indicates that even if the LINE/SINE elements in E. histolytica contain DNA methylation they do not necessarily co-regulate adjacent genes by this mechanism.

Additionally, we identified that adjacent loci in the same scaffold did not show co-regulation by DNA methylation (data not shown). This phenomenon is also observed in Arabidopsis thaliana, in which transcriptional profiling reveals that 5-Aza-dC responsive genes are distributed randomly throughout the chromosome arms and are not clustered in any obvious pattern [26].

\section{Effect of 5-AzaC on E. histolytica virulence}

Virulent strains of E. histolytica HM-1:IMSS and 200:NIH grown with $23 \mu \mathrm{M}$ of 5 -AzaC for three or seven days showed no substantial growth differences but displayed severely reduced virulence phenotype compared to untreated parasites (Figure 1) [15]. Importantly, others have demonstrated that the effect of 5-AzaC on parasite virulence is reversible and parasite virulence returns to baseline when drug exposure is withdrawn [15]. Whether the effect of 5-AzaC on parasite virulence is simply an associative or causal finding is unclear at present. However, we did find some genes that were down regulated in 5 -AzaC treated parasites, which have previously been shown to function as virulence determinants (Table 3 ). These included a putative cysteine proteinase (2.m00545), lysozyme (52.m00148), and a myosin Cabinding protein (1.m00663). Cysteine proteinases (CP) are important virulence determinants in E. histolytica and serve a number of functions including degradation of colonic mucin and extracellular matrix [56]. Genetic proof of their importance in virulence has been shown as parasites in which members of the CP family are down regulated are less virulent in vitro and in vivo $[57,58]$. Lysozymes are important for degrading intracellular bacteria and thus play an important role in E. histolytica virulence [59]. Motility is an important aspect of amebic pathogenesis and parasites that are altered in their myosin II are less virulent [60]. Likewise, Toxoplasma gondii myosin A has been implicated in powering parasite gliding and host cell invasion [61]. In addition, five protein kinase genes and eight GTPase family protein genes were also down regulated significantly in 5-AzaC treated parasites. Protein kinases can affect the functions of a large number of genes and the GTPase gene family is important in vesicle trafficking, an important aspect of biology in the professionally phagocytic E. histolytica [62]. Thus, some roles of these genes in amebic pathogenesis can be anticipated, although functional genetic proof will be necessary to assign a definitive role to these genes in amebic virulence.
Importantly, eight of the genes down regulated under 5AzaC treatment also had decreased expression in a nonvirulent strain of E. histolytica, Rahman, compared to the virulent E. histolytica HM-1:IMSS (108.m00122, 136.m00107, 22.m00298, 297.m00061，32.m00239, 37.m00215, 442.m00023, and 460.m00024) (Table 3) [31,63]. Interestingly, in E. histolytica Rahman, treatment with $23 \mu \mathrm{M}$ 5-AzaC did not significantly change the transcriptional profile of these genes (data not shown). A number of genes that have decreased expression in avirulent Entamoeba strains and species have been shown to be virulence determinants including the Gal/GalNAc light subunit lectin [64], CP1 and CP5 [56-58], and amebapore [32]. In addition, four genes down regulated by 5 -AzaC treatment (15.m00302, 2.m00545, 67.m00091, and 71.m00153) are significantly up regulated during parasite invasion in a mouse model of amebic colitis (Table 3 ) [27]. Since E. histolytica trophozoites passed through a mouse model become more virulent, some of the upregulated genes from the in vivo mouse model of colitis may have direct roles in virulence. Thus, data from a number of different angles indicates that genes that are down regulated by 5 -AzaC treatment are good candidates on which to perform directed functional studies to elucidate their potential contributions to amebic virulence.

\section{Discussion}

Cytosine methylation is the most frequent endogenous modification of DNA in eukaryotes and is involved in regulating gene expression [1]. DNA methylation has been implicated as having a multitude of effects in Entamoeba histolytica, however, the extent of DNA methylation and its overall roles in epigenetic gene silencing in this parasite were unknown. Here we report for the first time whole genome transcriptional profiling of E. histolytica parasites treated with 5-AzaC, an inhibitor of DNA methyltransferase. Our findings indicate that 68 genes (about $0.7 \%$ of tested genes) are endogenously silenced by methylation in this parasite.

We identified DNA methylation in the coding regions of some E. histolytica genes and in some instances higher levels of cytosine methylation in the coding regions compared to the promoter regions. In the transcription initiation factor TFIID gene (115.m00143) we only identified methylation in the coding region and yet this gene was transcriptionally silenced by endogenous methylation. This is consistent with the observation that DNA methylation within the body of genes may also have a dampening effect on transcriptional elongation. It has been suggested that methyl binding proteins might be involved in inhibiting elongation, either directly or by their effects on the surrounding chromatin structure [44]. A recent report of DNMT2 protein having a novel tRNA methyltransferase activity in mouse, Arabidopsis, and Dro- 
sophila suggests that the biological role of this protein is broader than was previously anticipated [65]. Interestingly, the cytoplasmic localization of the DNMT2 protein in mammalian cells is in contrast to the nuclear localization seen in E. histolytica [15]. It is not currently known whether the E. histolytica DNMT2 may also have a tRNA methyltransferase activity.

The E. histolytica genome is littered with retrotransposon elements of the LINE and SINE category. As a measure of genome defense, organisms often methylate these elements (and adjacent genes) in an attempt to silence them and prevent adverse effects of random transposition (reviewed in [3]). Our analysis indicates that in E. histolytica HM-1:IMSS genomic regions adjacent to the LINE and SINE elements are not significantly modulated by treatment with 5-AzaC. However, methylation of some LINE elements in Entamoeba have been reported and a DNA methylation based mechanism for controlling these elements is anticipated [52]. Thus, either the methylation is specific to the LINE elements (which we were not able to address in our analysis as the arrays do not contain probes for these regions) and does not spread to adjacent genomic regions, or the adjacent loci have a methylation pattern that is resistant to $23 \mu \mathrm{M} 5$-AzaC treatment. Additionally, although a LINE element was identified as being methylated (initially isolated using affinity chromatography and an anti-5-methyl cytosine antibody) attempts to identify a specific genomic copy of the LINE element that is methylated in E. histolytica have been unsuccessful to date [52]. Taken together the data indicate that methylation is involved to some degree in controlling LINEs in $E$. histolytica, but is likely not a genome-wide phenomenon and that other mechanisms to control retrotransposition in E. histolytica likely exist.

Despite the relatively few changes in gene expression induced by 5-AzaC treatment ( 68 genes upregulated and 131 genes down-regulated), there was marked reduction in monolayer destruction by two virulent strains of $E$. histolytica (HM-1:IMSS and 200:NIH). Since the two parasite strains are genetically distinct [30] and have unique expression profiles [63], the consistent effects of 5-AzaC treatment on amebic phenotype are interesting. Thus, genes that had differential expression in 5-AzaC treated parasites (especially those whose expression decreased by 5 -AzaC treatment) deserve further directed functional studies to characterize their potential roles in parasite virulence. Importantly, it has previously been reported that the decrease in parasite virulence by exposure to 5-AzaC was reversible upon removal of the drug, suggesting that drug exposure likely did not impart significant permanent mutations in the E. histolytica genome [15].
Our findings indicate that, although DNA methylation is operational in E. histolytica, this epigenetic mechanism of gene expression regulation affects a relatively small portion of amebic genes.

\section{Conclusion}

DNA methylation has roles in many crucial biological functions including regulation of gene expression. The genome-wide extent of DNA methylation and its subsequent effects on gene expression are unknown in many eukaryotes. We investigated the effects of DNA methylation in the protozoan parasite Entamoeba histolytica using whole genome expression profiling of parasites treated with 5-azacytidine, a potent inhibitor of DNA methyltransferase. Drug treatment modulated the expression of $\sim 2.1 \%$ of all amebic genes including 68 genes that were up-regulated and 131 genes that were down regulated.

\section{Methods}

\section{Parasite culture, 5-AzaC treatment, and growth curves}

Trophozoites of E. histolytica HM-1:IMSS and E. histolytica 200:NIH were maintained under axenic conditions in trypticase-yeast extract iron-serum medium (TYI-S-33) supplemented with 15\% adult bovine serum (Sigma), at $36.5^{\circ} \mathrm{C}$ as previously described [66]. The identity of both strains was confirmed by strain-specific PCR and RFLP analysis [67]. Trophozoites in log phase of growth were used in all experiments. To inhibit genomic DNA methylation, E. histolytica trophozoites were grown with $23 \mu \mathrm{M} 5$ AzaC (TRC, Canada) for up to one week with routine subculturing performed every 48 hours. For the growth curves 50,000 log-phase trophozoites were inoculated in $15 \mathrm{ml}$ of TYI-S-33 media in the presence or absence of $23 \mu \mathrm{M} 5$ AzaC, grown under standard culture conditions as outlined above, and the parasite number recorded every 24hours. Growth curves were performed a minimum of three times. To grow parasites without subculturing, we seeded 15,000 log-phase trophozoites in $15 \mathrm{ml}$ of TYI-S33 media in the presence or absence of $23 \mu \mathrm{M} 5$-AzaC under standard culture conditions and monitored the parasite count every day up to day 5. In order to further assess the growth kinetics of the parasites in $23 \mu \mathrm{M}$ 5-AzaC, 50,000 log-phase trophozoites were seeded in $15 \mathrm{ml}$ of TYI-S33 media in the presence or absence of $23 \mu \mathrm{M} 5$-AzaC and subcultured every two days with equal inoculums of media and parasites being passed each time. Cell counts were recorded at days 2, 4, and 6 after initiation of growth in 5-AzaC.

\section{Protein concentration determination}

Protein concentration was determined using the method of Bradford [68]. Briefly, trophozoites were lysed on ice for 2 min using Cell Culture Lysis Reagent (Promega) supplemented with protease inhibitors (500 $\mu \mathrm{M}$ AEBSF, $1 \mu \mathrm{M}$ leupeptin, $1 \mu \mathrm{M}$ E-64d). Cell membranes were pelleted by 
centrifugation for $30 \mathrm{sec}$ at $14,000 \times \mathrm{g}$. A standard curve for the Bradford assay was determined using bovine serum albumin as a reference. Protein concentration of the cell lysate was determined relative to this standard curve. The protein concentration (ng/cell) was determined for each time point of interest.

\section{Chinese Hamster Ovary (CHO) cell culture and in vitro CHO cell monolayer destruction assay}

CHO cells were maintained in Dulbecco's minimal essential media (DMEM) supplemented with 10\% fetal bovine serum, penicillin $(100 \mathrm{U} / \mathrm{ml})$, and streptomycin $(100 \mu \mathrm{g} /$ $\mathrm{ml}$ ). CHO cell monolayer destruction by E. histolytica trophozoites was performed according to Bracha and Mirelman [69] with some modifications. Briefly 200,000 trophozoites of E. histolytica strain HM-1:IMSS or 200:NIH grown with or without $23 \mu \mathrm{M}$ of 5-AzaC for three or seven days were incubated with confluent $\mathrm{CHO}$ cell monolayers in 24-well plates in 3 mls of DMEM (containing no serum) at $36.5^{\circ} \mathrm{C}$ for 3 hours. The integrity of the CHO cell monolayer that remained attached to the 24well plate was determined by staining with methylene blue. The level of monolayer destruction was calculated to be inversely proportional to the amount of intact cells that remained attached to the 24-well plate. CHO cells incubated with DMEM or DMEM with $23 \mu \mathrm{M}$ 5-AzaC served as controls. All experiments were performed at least three times. Statistical analyses were performed using a twotailed Student's t-test and p-values $<0.05$ were considered statistically significant.

\section{Microarray expression profiling}

A custom E. histolytica Affymetrix array (E_his-1a520285) was designed using information from the E. histolytica genome sequencing project [27]. The ORF probe sets represent 9,435 of the predicted 9,938 E. histolytica ORFs [70]. Most of the highly repetitive sequences in E. histolytica such as LINEs, SINEs, rRNA genes, and tRNA genes were not included in the array as specific probe sets could not be designed. There are probe sets on the Affymetrix array representing selected intergenic regions, but these were not included in the analyses described in this paper.

Total RNA was isolated from log phase trophozoites of $E$. histolytica HM-1:IMSS and the same strain grown with 23 $\mu \mathrm{M}$ 5-AzaC for three or seven days using Trizol reagent (Invitrogen). RNA was cleaned using the RNAeasy kit (QIAGEN) according to the manufacturer's instructions and $4 \mu \mathrm{g}$ processed for hybridization to the E. histolytica Affymetrix array through the Stanford University Protein and Nucleic Acid Biotechnology Facility [71] using standard Affymetrix protocols. Two arrays were generated for HM-1:IMSS parasites (not treated with drug) under midlog conditions and two arrays were generated from HM1:IMSS parasites treated with 5-AzaC (one each from three and seven days of treatment). Each microarray was generated from RNA harvested from parasites on different days and thus represent independent biological replicates.

\section{Microarray data analysis}

The raw signal intensities were scaled by GCOS software so that the average of all of the probe sets on an array was 500. All data for intergenic regions was removed prior to any further analysis. The remaining data were analyzed using the GeneSpring ${ }^{\circledR} 7$ software [72]. A global normalization was performed per chip to the median excluding the probe sets flagged absent. All the normalized expression values were averaged between the two arrays from untreated parasites (control group), and between the two arrays from three day and seven day 5-AzaC-treated parasites (treated group). We assumed that the expression variances were equal for two arrays within a particular group. To eliminate genes that were not expressed under either of the two conditions, we filtered out probe sets that had an average normalized expression value of $<0.1$ in both groups analyzed (control and 5-AzaC-treated) as we have previously determined that genes with that expression level are not routinely detectable by RT-PCR (our unpublished observations). In order to identify genes that were significantly modulated in presence of 5 -AzaC we used two criteria: (1) expression fold change $\geq 2$-fold, and (2) a p-value $<0.05$.

\section{RNA isolation and RT-PCR}

Total RNA was extracted from log phase E. histolytica HM1:IMSS parasites using TRIZOL (Invitrogen) reagent according to the manufacturer's instructions. DNA contamination in the RNA preparation was removed by DNAse treatment. Reverse transcription was performed to generate cDNA for RT-PCR using SuperScript ${ }^{\mathrm{TM}}$ II Reverse Transcriptase kit (Invitrogen) according to the manufacturer's instructions. PCR was performed with serial 10fold dilutions of cDNA; a negative control was included with each reaction. Primers used in RT-PCR are listed in Table 1.

\section{Sodium bisulfite treatment and PCR amplification}

E. histolytica HM-1:IMSS genomic DNA was isolated using standard Phenol:Chloroform method, and RNA contamination was removed by treating with RNaseA (Invitrogen) [30]. Sodium bisulfite treatment of E. histolytica genomic DNA $(\sim 2 \mu \mathrm{g})$ was performed according to the method described by Clark and Warnecke [43]. For each sample, following bisulfite treatment, two PCR amplifications were performed, each consisting of 50 cycles. Primers used to amplify promoters and genomic regions following bisulfite treatment are listed in Table 1. PCR amplified fragments derived from sodium bisulfite treated DNA were resolved on a $1.2 \%$ agarose gel, appropriate fragments excised and purified using QIAEX ${ }^{\circledR}$ II Gel Extraction 
Kit (QIAGEN) according to the manufacturer's instructions. Purified DNA fragments were cloned into TOPO TA vector (Invitrogen), transformed into competent Escherichia coli (Invitrogen), plasmid DNA isolated using QIAprep Miniprep Kit (QIAGEN), and sequenced using an ABI PRISM 310 genetic analyzer (PE Applied Biosystems) (Macrogen, Korea). Six plasmid clones were sequenced for each gene fragment.

\section{Genome structure analysis of genes modulated by 5-AzaC treatment}

In order to determine the frequency of mono and dinucleotides in the genomic regions affected by 5 -AzaC treatment we performed the following analysis. Sequences for the promoter ( $500 \mathrm{bp}$ upstream of the predicted start codon) and coding regions of all genes modulated by 5 -AzaC treatment were downloaded from The Institute for Genomic Research (TIGR) website [35]. Additionally, the sequence of the most recent assembly (12/ 27/05) of the genome sequence was also obtained [35]. Using acustom script written in the Python programming language by JAH (see Additional file 3 ) we determined the mono and di-nucleotide frequency in the promoter and coding regions of genes up-regulated by 5 -AzaC treatment, down-regulated by 5 -AzaC treatment, and the entire genome.

To determine if the genes modulated by 5-AzaC treatment were adjacent to the retrotransposon elements (LINEs and SINEs), all occurrences of the three families of EhLINEs and EhSINEs were identified in the E. histolytica genome sequence using BLAST program [73] and the consensus sequence of the LINEs and SINEs [55] with an e-value cutoff of $10^{-20}$. The frequency of occurrence of each LINE and SINE gene family member was similar to the results identified previously [55]. We subsequently identified all genes adjacent (within $10 \mathrm{~Kb}$, both upstream and downstream) to each member of EhLINE or EhSINE, considering only the gene most proximal to a given LINE or SINE. Using the hypergeometric distribution, we determined if the genes modulated by 5 -AzaC treatment were more likely to be adjacent to an EhLINE or EhSINE element than by random chance ( $\mathrm{p}$-value $<0.05$ ).

\section{List of abbreviations}

5-AzaC, 5-azacytidine; 5-Aza-dC, 5-aza-2-deoxycytidine; PCR, polymerase chain reaction; RT-PCR, reverse-transcription-PCR; LINE, long interspersed nuclear element; SINE, short interspersed nuclear element; Ehmeth, Entamoeba histolytica methyltransferase; DNMTs, DNA methyltransferases; MBD, Methyl binding domain; m5C, C5cytosine; DMEM, Dulbecco's minimal essential media; $\mathrm{CHO}$, Chinese Hamster Ovary; ORF, open reading frame.

\section{Authors' contributions}

IKMA and US designed the experiments and wrote the manuscript. IKMA performed the experiments, GME assisted with microarray experiments and analysis, and JAH provided bioinformatic analyses. All authors have read and approved the final manuscript.

\section{Additional material}

\section{Additional File 1}

(A) E. histolytica HM-1:IMSS grown in $23 \mu \mathrm{M} 5$-AzaC for five consecutive days have similar growth kinetics to untreated parasites. E. histolytica HM-1:IMSS log-phase trophozoites $(15,000)$ were seeded into $15 \mathrm{ml}$ glass culture tubes, cultured under standard conditions $\pm 23 \mu \mathrm{M} 5-A z a C$, and cell counts taken at days 2,3,4, and 5. The average and standard deviation values for each time point are shown for untreated and 5-AzaC treated parasites. There were no statistical differences in the cell counts at any given time point in 5-AzaC treated and untreated parasites. One representative experiment is shown. (B) Protein content per cell was determined at days 2,3, 4, and 5 of parasite growth $\pm 23 \mu \mathrm{M} 5-A z a C$ treatment for E. histolytica HM-1:IMSS parasites. The average and standard deviation values for each time point are shown. There were no statistically significant differences in the protein concentration per cell at any given time point in 5-AzaC treated and untreated parasites or in parasites grown for 2, 3, 4, or 5 days. One representative experiment is shown. (C) E. histolytica HM-1:IMSS grown in $23 \mu \mathrm{M} 5$-AzaC for six days with routine subculturing of equal volume of media/parasites have similar growth kinetics to untreated parasites after two days in 5-AzaC. E. histolytica HM-1:IMSS log-phase trophozoites $(50,000)$ were seeded into $15 \mathrm{ml}$ glass culture tubes and cultured under standard conditions \pm $23 \mu \mathrm{M}$ 5-AzaC. At days 2 and 4 (marked with a down arrow) an equal volume of media containing parasites grown $\pm 5-A z a C$ was inoculated into a new tube with fresh media $( \pm 5-A z a C)$ and cell counts obtained at days 2, 4, and 6. The average and standard deviation values for each time point are shown for untreated and 5-AzaC treated parasites. One representative experiment is shown.

Click here for file

[http://www.biomedcentral.com/content/supplementary/14712164-8-7-S1.doc]

\section{Additional File 4}

Normalized expression values for arrays from untreated and 5-AzaC treated E. histolytica HM-1:IMSS parasites. All array data have been made available per MIAME guidelines. Raw array data have been deposited at the NCBI Gene Expression Omnibus website (accession number GSE6635).

Click here for file

[http://www.biomedcentral.com/content/supplementary/14712164-8-7-S4.xls]

\section{Additional File 2}

Verification of array data for EHsp100 (represented on the microarray by the probe set 64.m00187_s_at) by semi-quantitative RT-PCR. Total RNA was isolated from untreated and $5-A z a C$ treated parasites ( 7 days) and subjected to RT-PCR. Sequential 1:100 dilutions of cDNA were used as template for the PCR and a genomic DNA and minus RT control (-RT) were included. The microarray expression fold-change for each gene is shown based on average array data from 3-day and 7-day 5-AzaC treated parasites. Primers specific to the EHsp100 gene (192.m00086) as determined by Bernes et al [16] were used for the RT-PCR reaction. A gene whose expression did not change based on array data (147.m00095) was found to be unchanged in the two conditions by RT-PCR.

Click here for file

[http://www.biomedcentral.com/content/supplementary/14712164-8-7-S2.ppt] 


\section{Additional File 3}

This Python script determines the frequencies of mono- and dinucleotides in a FASTA sequence file. This program requires a Python interpreter installed on the computer that is being used for this analysis, which can be freely downloaded [74]. Download the text of this file exactly as written (including white space). To run the program, type "python <name of script file $><$ name of FASTA sequence file $>$ ".

Click here for file

[http://www.biomedcentral.com/content/supplementary/14712164-8-7-S3.ppt]

\section{Acknowledgements}

We gratefully acknowledge all members of the Singh lab for helpful comments and suggestions. US was supported in part by NIH grants Al-053724 and Al-3794I, IKMA was supported in part by a Stanford University Dean's Fellowship and by NIH grant AI-053724, JAH was supported by the NIH grants T32-A107502 and T32-AI07328, and GME was supported by NIH grants T32-A107502 and Al-068899, and a Stanford University Dean's Fellowship. US is a member of the Stanford University Digestive Disease Center, which is supported by NIH grant P30 DK56339.

\section{References}

I. Razin A, Cedar H: DNA methylation and gene expression. Microbiol Rev 1991, 55(3):45।-458.

2. Katoh M, Curk T, Xu Q, Zupan B, Kuspa A, Shaulsky G: Developmentally regulated DNA methylation in Dictyostelium discoideum. Eukaryot Cell 2006, 5(I): 18-25.

3. Yoder JA, Walsh CP, Bestor TH: Cytosine methylation and the ecology of intragenomic parasites. Trends Genet 1997, I 3(8):335-340.

4. Robertson KD: DNA methylation and chromatin - unraveling the tangled web. Oncogene 2002, 21 (35):5361-5379.

5. Goto T, Monk M: Regulation of X-chromosome inactivation in development in mice and humans. Microbiol Mol Biol Rev 1998, 62(2):362-378.

6. Dodge JE, Ramsahoye BH, Wo ZG, Okano M, Li E: De novo methylation of MMLV provirus in embryonic stem cells: $C p G$ versus non-CpG methylation. Gene 2002, 289(I-2):4I-48.

7. Comb M, Goodman HM: CpG methylation inhibits proenkephalin gene expression and binding of the transcription factor AP-2. Nucleic Acids Res 1990, I 8(13):3975-3982.

8. Inamdar NM, Ehrlich KC, Ehrlich M: CpG methylation inhibits binding of several sequence-specific DNA-binding proteins from pea, wheat, soybean and cauliflower. Plant Mol Biol I99I, 17(I):III-123.

9. Jones PL, Veenstra GJ, Wade PA, Vermaak D, Kass SU, Landsberger N, Strouboulis J, Wolffe AP: Methylated DNA and MeCP2 recruit histone deacetylase to repress transcription. Nat Genet 1998, 19(2):|87-191.

10. Nan X, Ng HH, Johnson CA, Laherty CD, Turner BM, Eisenman RN, Bird A: Transcriptional repression by the methyl-CpG-binding protein MeCP2 involves a histone deacetylase complex. Nature 1998, 393(6683):386-389.

II. Esteller M, Fraga MF, Guo M, Garcia-Foncillas J, Hedenfalk I, Godwin AK, Trojan J, Vaurs-Barriere C, Bignon YJ, Ramus S, et al.: DNA methylation patterns in hereditary human cancers mimic sporadic tumorigenesis. Hum Mol Genet 200I, I 0(26):300 I-3007.

12. Sharma RP: Schizophrenia, epigenetics and ligand-activated nuclear receptors: a framework for chromatin therapeutics. Schizophr Res 2005, 72(2-3):79-90.

13. Liu L, Wylie RC, Andrews LG, Tollefsbol TO: Aging, cancer and nutrition: the DNA methylation connection. Mech Ageing Dev 2003, I 24( I 0- I 2):989-998

14. WHO/PAHO/UNESCO report. A consultation with experts on amoebiasis. Mexico City, Mexico 28-29 January, 1997. Epidemiol Bull 1997, I8(1):13-4.
15. Fisher O, Siman-Tov R, Ankri S: Characterization of cytosine methylated regions and 5-cytosine DNA methyltransferase (Ehmeth) in the protozoan parasitec Entamoeba histolytica. Nucleic Acids Res 2004, 32(I):287-297.

16. Bernes S, Siman-Tov R, Ankri S: Epigenetic and classical activation of Entamoeba histolytica heat shock protein 100 (EHsp I 00) expression. FEBS Lett 2005, 579(28):6395-6402.

17. Lavi T, Isakov E, Harony H, Fisher O, Siman-Tov R, Ankri S: Sensing DNA methylation in the protozoan parasite Entamoeba histolytica. Mol Microbiol 2006

18. Fisher O, Siman-Tov R, Ankri S: Pleiotropic phenotype in Entamoeba histolytica overexpressing DNA methyltransferase (Ehmeth). Mol Biochem Parasitol 2006, I47(I):48-54.

19. Rojas MV, Galanti N: Relationship between DNA methylation and cell proliferation in Trypanosoma cruzi. FEBS Lett I99|, 295(I-3):3I-34

20. Juranek S, Wieden HJ, Lipps HJ: De novo cytosine methylation in the differentiating macronucleus of the stichotrichous ciliate Stylonychia lemnae. Nucleic Acids Res 2003, 3 I (5): | 387-I39|.

21. Palacios G, Martin-Gonzalez A, Gutierrez JC: Macronuclear DNA demethylation is involved in the encystment process of the ciliate Colpoda inflata. Cell Biol Int 1994, 18(4):223-228.

22. Yamashita S, Tsujino $\mathrm{Y}$, Moriguchi K, Tatematsu M, Ushijima T: Chemical genomic screening for methylation-silenced genes in gastric cancer cell lines using 5-aza-2'-deoxycytidine treatment and oligonucleotide microarray. Cancer Sci 2006 , 97(I):64-7I.

23. Suzuki H, Gabrielson E, Chen W, Anbazhagan R, van Engeland M, Weijenberg MP, Herman JG, Baylin SB: A genomic screen for genes upregulated by demethylation and histone deacetylase inhibition in human colorectal cancer. Nat Genet 2002, $31(2): 14|-| 49$.

24. Yamashita K, Upadhyay S, Osada M, Hoque MO, Xiao Y, Mori M, Sato F, Meltzer SJ, Sidransky D: Pharmacologic unmasking of epigenetically silenced tumor suppressor genes in esophageal squamous cell carcinoma. Cancer Cell 2002, 2(6):485-495.

25. Pompeia C, Hodge DR, Plass C, Wu YZ, Marquez VE, Kelley JA, Farrar WL: Microarray analysis of epigenetic silencing of gene expression in the KAS-6/I multiple myeloma cell line. Cancer Res 2004, 64( I 0):3465-3473.

26. Chang S, Pikaard CS: Transcript profiling in Arabidopsis reveals complex responses to global inhibition of DNA methylation and histone deacetylation. J Biol Chem 2005, 280(I):796-804.

27. Gilchrist CA, Houpt E, Trapaidze N, Fei Z, Crasta O, Asgharpour A, Evans C, Martino-Catt S, Baba DJ, Stroup S, et al.: Impact of intestinal colonization and invasion on the Entamoeba histolytica transcriptome. Mol Biochem Parasitol 2006, 147(2): 163-176.

28. Orozco E, Martinez-Palomo A, Lopez-Revilla R: [An in vitro model for the quantitative study of $E$. histolytica virulence]. Arch Invest Med (Mex) I 978, 9(Suppl I):257-260.

29. Ghadirian E, Meerovitch E: Pathogenicity of axenically cultivated Entamoeba histolytica, strain 200: $\mathrm{NIH}$, in the hamster. J Parasitol |979, 65(5):768-77|.

30. Shah PH, MacFarlane RC, Bhattacharya D, Matese JC, Demeter J, Stroup SE, Singh U: Comparative genomic hybridizations of Entamoeba strains reveal unique genetic fingerprints that correlate with virulence. Eukaryot Cell 2005, 4(3):504-5I5.

31. MacFarlane RC, Singh U: Identification of differentially expressed genes in virulent and nonvirulent Entamoeba species: potential implications for amebic pathogenesis. Infect Immun 2006, 74(I):340-35I.

32. Anbar M, Bracha R, Nuchamowitz Y, Li Y, Florentin A, Mirelman D: Involvement of a short interspersed element in epigenetic transcriptional silencing of the amoebapore gene in Entamoeba histolytica. Eukaryot Cell 2005, 4(I I): 1775-1784.

33. Li M, Ou X, Lee TD, Zeng Y, Mato JM, Lu SC: Silencing of human methionine adenosyltransferase IA expression by methylation of the coding region. J Biol Chem 2004.

34. Banerjee S, Fisher O, Lohia A, Ankri S: Entamoeba histolytica DNA methyltransferase (Ehmeth) is a nuclear matrix protein that binds EhMRS2, a DNA that includes a scaffold/matrix attachment region (S/MAR). Mol Biochem Parasitol 2005, I39(I):9|-97.

35. Entamoeba histolytica Genome Project [http://www.tigr.org/ $\underline{\mathrm{tdb} / \mathrm{e} 2 \mathrm{kl} / \mathrm{ehal} / \mathrm{s}}$ 
36. Bracha R, Nuchamowitz Y, Anbar M, Mirelman D: Transcriptional silencing of multiple genes in trophozoites of Entamoeba histolytica. PLOS Pathog 2006, 2(5):e48.

37. Platt GM, Price C: Isolation of a Schizosaccharomyces pombe gene which in high copy confers resistance to the nucleoside analogue 5-azacytidine. Yeast 1997, I3(5):463-474.

38. Mathieu O, Bender J: RNA-directed DNA methylation. J Cell Sc 2004, I I 7(Pt 2 I ):488I-4888.

39. Hubacek J: Biological function of DNA methylation. Folia Microbiol (Praha) 1992, 37(5):323-329.

40. Doskocil J, Sormo'Va Z: The Occurrence Of 5-Methylcytosine In Bacterial Deoxyribonucleic Acids. Biochim Biophys Acta 1965 , 95:5|3-5|5.

4I. Dunn DB, Smith JD: The occurrence of 6-methylaminopurine in deoxyribonucleic acids. Biochem / 1958, 68(4):627-636.

42. Ehrlich M, Gama-Sosa MA, Carreira LH, Ljungdahl LG, Kuo KC Gehrke CW: DNA methylation in thermophilic bacteria: N4 methylcytosine, 5-methylcytosine, and N6-methyladenine. Nucleic Acids Res 1985, I3(4): 1399-1412.

43. Clark SJ, Warnecke PM: DNA methylation analysis in mammalian cells. Methods 2002, 27(2):99-100.

44. Lorincz MC, Dickerson DR, Schmitt M, Groudine M: Intragenic DNA methylation alters chromatin structure and elongation efficiency in mammalian cells. Nat Struct Mol Biol 2004 I I(I I): I068-1075.

45. Borsatti F, Casarini L, Mandrioli M: Analysis of the expression pattern of the defensin gene in the lepidopteran Mamestra brassicae. Invert Surv J 2004, I:34-37 [http://www.isj.unimo.it/ voll issuel.htm]

46. Hick CA, Field LM, Devonshire AL: Changes in the methylation of amplified esterase DNA during loss and reselection of insecticide resistance in peach-potato aphids, Myzus persicae. Insect Biochem Mol Biol 1996, 26(I):4I-47

47. Field LM: Methylation and expression of amplified esterase genes in the aphid Myzus persicae (Sulzer). Biochem J 2000, 349(Pt 3):863-868

48. Bongiorni S, Cintio $O$, Prantera $G$ : The relationship between DNA methylation and chromosome imprinting in the coccid Planococcus citri. Genetics 1999, I5 I(4): I47|-|478.

49. Bongiorni S, Prantera G: Imprinted facultative heterochromatization in mealybugs. Genetica 2003, I I 7(2-3):27I-279.

50. Klose RJ, Bird AP: Genomic DNA methylation: the mark and its mediators. Trends Biochem Sci 2006, 3 I (2):89-97.

51. Eichinger L, Noegel AA: Comparative genomics of Dictyostelium discoideum and Entamoeba histolytica. Curr Opin Microbiol 2005, 8(5):606-6II

52. Harony H, Bernes S, Siman-Tov R, Ankri S: DNA methylation and targeting of LINE retrotransposons in Entamoeba histolytica and Entamoeba invadens. Mol Biochem Parasitol 2006, I47(I):55-63.

53. Thornburg BG, Gotea V, Makalowski W: Transposable elements as a significant source of transcription regulating signals. Gene 2006, 365:104-110.

54. Park CW, Kren BT, Largaespada DA, Steer CJ: DNA methylation of Sleeping Beauty with transposition into the mouse genome. Genes Cells 2005, I 0(8):763-776.

55. Bakre AA, Rawal K, Ramaswamy R, Bhattacharya A, Bhattacharya S The LINEs and SINEs of Entamoeba histolytica : comparative analysis and genomic distribution. Exp Parasitol 2005 , I I 0(3):207-2 I3.

56. Que X, Reed SL: Cysteine proteinases and the pathogenesis of amebiasis. Clin Microbiol Rev 2000, I3(2):196-206.

57. Ankri S, Stolarsky T, Mirelman D: Antisense inhibition of expression of cysteine proteinases does not affect Entamoeba histolytica cytopathic or haemolytic activity but inhibits phagocytosis. Mol Microbiol 1998, 28(4):777-785.

58. Ankri S, Stolarsky T, Bracha R, Padilla-Vaca F, Mirelman D: Antisense inhibition of expression of cysteine proteinases affects Entamoeba histolytica-induced formation of liver abscess in hamsters. Infect Immun 1999, 67( I):421-422

59. Jacobs T, Leippe M: Purification and molecular cloning of a major antibacterial protein of the protozoan parasite Entamoeba histolytica with lysozyme-like properties. Eur J Biochem 1995, 23 I(3):83|-838.

60. Coudrier E, Amblard F, Zimmer C, Roux P, Olivo-Marin JC, Rigothier MC, Guillen N: Myosin II and the Gal-GalNAc lectin play a cru- cial role in tissue invasion by Entamoeba histolytica. Cell Microbiol 2005, 7(I): 19-27.

61. Meissner M, Schluter D, Soldati D: Role of Toxoplasma gondi myosin A in powering parasite gliding and host cell invasion. Science 2002, 298(5594):837-840.

62. Saito-Nakano Y, Loftus BJ, Hall N, Nozaki T: The diversity of Rab GTPases in Entamoeba histolytica. Exp Parasitol 2005 I I 0(3):244-252.

63. Ehrenkaufer G, Hauqe R, Hackney J, Eichinger D, Singh U: Identification of developmentally regulated genes in Entamoeba histolytica: insights into mechanisms of stage conversion in a protozoan parasite. Cellular Microbiology in press.

64. Gilchrist CA, Petri WA: Virulence factors of Entamoeba histolytica. Curr Opin Microbiol 1999, 2(4):433-437.

65. Goll MG, Kirpekar F, Maggert KA, Yoder JA, Hsieh CL, Zhang X Golic KG, Jacobsen SE, Bestor TH: Methylation of tRNAAsp by the DNA methyltransferase homolog Dnmt2. Science 2006 , 3 I I(5759):395-398.

66. Diamond LS, Harlow DR, Cunnick CC: A new medium for the axenic cultivation of Entamoeba histolytica and other Entamoeba. Trans R Soc Trop Med Hyg 1978, 72(4):43 I-432.

67. Clark CG, Diamond LS: Entamoeba histolytica : a method for isolate identification. Exp Parasitol 1993, 77(4):450-455

68. Bradford MM: A rapid and sensitive method for the quantitation of microgram quantities of protein utilizing the principle of protein-dye binding. Anal Biochem 1976, 72:248-254.

69. Bracha R, Mirelman D: Virulence of Entamoeba histolytica trophozoites. Effects of bacteria, microaerobic conditions, and metronidazole. J Exp Med 1984, I 60(2):353-368.

70. Loftus B, Anderson I, Davies R, Alsmark UC, Samuelson J, Amedeo P, Roncaglia P, Berriman M, Hirt RP, Mann BJ, et al.: The genome of the protist parasite Entamoeba histolytica. Nature 2005, 433(7028):865-868.

7I. Stanford Protein and Nucleic Acid Biotechnology Facility [http://cmgm.stanford.edu/pan/index.html]

72. GeneSpring software [http://www.silicongenetics.com]

73. Entamoeba histolytica sequence BLAST search [http:// tigrblast.tigr.org/er-blast/index.cgi?project=eha I]

74. Python [http://www.python.org]

Publish with Biomed Central and every scientist can read your work free of charge

"BioMed Central will be the most significant development for disseminating the results of biomedical research in our lifetime. "

Sir Paul Nurse, Cancer Research UK

Your research papers will be:

- available free of charge to the entire biomedical community

- peer reviewed and published immediately upon acceptance

- cited in PubMed and archived on PubMed Central

- yours - you keep the copyright
BioMedcentral 